\title{
Modelling the future biogeography of North Atlantic zooplankton communities in response to climate change
}

\author{
Ernesto Villarino ${ }^{1, *}{ }^{,}$, Guillem Chust ${ }^{1}$, Priscilla Licandro ${ }^{2}$, Momme Butenschön ${ }^{3}$, \\ Leire Ibaibarriaga ${ }^{1}$, Aitor Larrañaga ${ }^{4}$, Xabier Irigoien ${ }^{5}$ \\ ${ }^{1}$ AZTI-Tecnalia, Marine Research Division, Txatxarramendi ugartea z/g, 48395 Sukarrieta (Bizkaia), Spain \\ ${ }^{2}$ Sir Alister Hardy Foundation for Ocean Science, The Laboratory, Citadel Hill, Plymouth PL1 2PB, UK \\ ${ }^{3}$ Plymouth Marine Laboratory (PML), Prospect Place, Plymouth PL1 3DH, UK \\ ${ }^{4}$ Laboratory of Stream Ecology, Department of Plant Biology and Ecology, University of the Basque Country, PO Box 644, \\ 48080 Bilbao, Spain
}

${ }^{5}$ Red Sea Research Center, King Abdullah University of Science and Technology (KAUST), Thuwal 23955-6900, Saudi Arabia

\begin{abstract}
Advances in habitat and climate modelling allow us to reduce uncertainties of climate change impacts on species distribution. We evaluated the impacts of future climate change on community structure, diversity, distribution and phenology of 14 copepod species in the North Atlantic. We developed and validated habitat models for key zooplankton species using continuous plankton recorder (CPR) survey data collected at mid latitudes of the North Atlantic. Generalized additive models (GAMs) were applied to relate the occurrence of species to environmental variables. Models were projected to future (2080-2099) environmental conditions using coupled hydroclimatic-biogeochemical models under the Intergovernmental Panel on Climate Change (IPCC) A1B climate scenario, and compared to present (2001-2020) conditions. Our projections indicated that the copepod community is expected to respond substantially to climate change: a mean poleward latitudinal shift of $8.7 \mathrm{~km}$ per decade for the overall community with an important species range variation ( -15 to $18 \mathrm{~km}$ per decade); the species seasonal peak is expected to occur 12-13 d earlier for Calanus finmarchicus and C. hyperboreus; and important changes in community structure are also expected (high species turnover of $43-79 \%$ south of the Oceanic Polar Front). The impacts of the change expected by the end of the century under IPCC global warming scenarios on copepods highlight poleward shifts, earlier seasonal peak and changes in biodiversity spatial patterns that might lead to alterations of the future North Atlantic pelagic ecosystem. Our model and projections are supported by a temporal validation undertaken using the North Atlantic climate regime shift that occurred in the 1980s: the habitat model built in the cold period (1970-1986) has been validated in the warm period (1987-2004).
\end{abstract}

KEY WORDS: Zooplankton · Habitat suitability · GAM · Climate change - North Atlantic · Biogeography Resale or republication not permitted without written consent of the publisher

\section{INTRODUCTION}

Plankton communities can quickly respond to climatic variability (e.g. Beaugrand et al. 2002a). Impacts of global warming affect the whole pelagic ecosystem from plankton to higher trophic levels (Richardson \& Schoeman 2004, Beaugrand \& Kirby 2010, Beaugrand 2012). Such impacts can result in poleward movements in species distribution (Johns et al. 2001, Perry et al. 2005, Parmesan 2006, Beau- 
grand et al. 2009, Chust et al. 2014a), shifts in phenology (Edwards \& Richardson 2004, Moore et al. 2011) or changes in abundance and community structure (Molinero et al. 2008, Kirby \& Beaugrand 2009, Chust et al. 2014b). Species responses to climate change may lead to local extinction and invasions, resulting in changes in the pattern of marine species richness and trophic mismatches (Cheung et al. 2009). Therefore, assessing how these biogeographic processes will change in the future is a key prerequisite to anticipate consequences of climate change on marine ecosystems.

Sea temperature is one of the most important physical variables structuring marine ecosystems. There is overwhelming evidence that the composition, abundance and phenology of plankton communities are closely linked to water temperature (Richardson 2008). Throughout the North Atlantic Ocean, a general increase in temperature has been observed in the past century (Beaugrand 2009) and future ocean temperatures have been forecasted to increase by coupled atmosphere-ocean general circulation models (AOGCMs). In particular, the North Atlantic has warmed faster than all other ocean basins, and climate change scenarios project sea surface temperature isotherms to shift up to $600 \mathrm{~km}$ northwards by the end of the 21st century (Lee et al. 2011).

Habitat suitability (species distribution) models (Guisan \& Zimmermann 2000, Elith \& Leathwick 2009) have been widely used to project how species ranges might change in the future. These models aim to define the species ecological niches by relating the occurrence of species to environmental variables (e.g. temperature, depth and phytoplankton) in the same area. They rely on the environmental niche concept of Hutchinson (1957), in which a multi-dimensional hypervolume is defined by the combination of multiple environmental conditions required by a species population to survive and reproduce. Habitat suitability models have been widely used to project how species ranges might change in the future. Then, using projections from the Intergovernmental Panel on Climate Change (IPCC), we can investigate how environmental changes will affect future species distributions (Guisan \& Thuiller 2005).

In the past decade, several studies using species distribution models and continuous plankton recorder (CPR) data with future climate change scenarios have been published. For example, Helaouët \& Beaugrand (2009) forecasted a poleward movement of Calanus finmarchicus of $1^{\circ}$ latitude by the end of the 21st century; Beaugrand et al. (2008) analysed the reasons behind the climate-driven ecosystem future shifts of cod, zooplankton and phytoplankton; Reygondeau \& Beaugrand (2011) and Beaugrand et al. (2011) used the Non-Parametric Probabilistic Ecological Niche Model (NPPENM) to project C. finmarchicus distribution through the next century; while Beaugrand et al. (2013) investigated how climateinduced changes in temperatures will alter marine zooplankton both locally and globally. Most of these studies have used the NPPENM, which is based on the Mahalanobis distance (MD) algorithm (Mahalanobis 1936). A recent work by Chust et al. (2014a) shows that generalized additive models (GAMs) perform well in detecting latitudinal shifts of species and identifying the causes.

So far most of the bioclimatological research is concentrated on a single species (Bonnet et al. 2005, Beaugrand et al. 2007, Helaouët \& Beaugrand 2007, Helaouët et al. 2011, Reygondeau \& Beaugrand 2011, Beaugrand et al. 2013) and there are very few works at community level (Beaugrand et al. 2000, 2002b, 2009, Beaugrand \& Ibañez 2002, Woodd-Walker et al. 2002). Yet, some of the publications analysed the historic plankton biogeographical shifts in the North Atlantic Ocean (e.g. Reygondeau \& Beaugrand 2011). However, little is known about the future spatial distribution of copepod biodiversity, seasonal changes and latitudinal shift in the North Atlantic Ocean, despite their importance in marine food webs.

Here, we analysed a zooplankton community to detect future biogeographic changes in species distribution and phenology, and to identify spatial and temporal patterns of diversity. This will allow us to project the community shifts and their consequences in the North Atlantic Basin. In particular, our aim was to develop and validate habitat models in key zooplankton species using CPR survey data collected at mid latitudes of the North Atlantic ( 35 to $65^{\circ} \mathrm{N}$, Fig. 1) to be reliably extrapolated to future climate scenarios. To do that, we built a model using the data from a cold period (1970-1986) and evaluated its performance under a warm regime (1987-2004). Subsequently, the model was used to project species distributions, community composition and phenological changes at the end of the century under climate change scenarios.

\section{MATERIALS AND METHODS}

\section{Environmental data}

A set of 7 environmental variables was used to build the $\mathrm{N}$-dimensional ecological niches of copepod spe- 


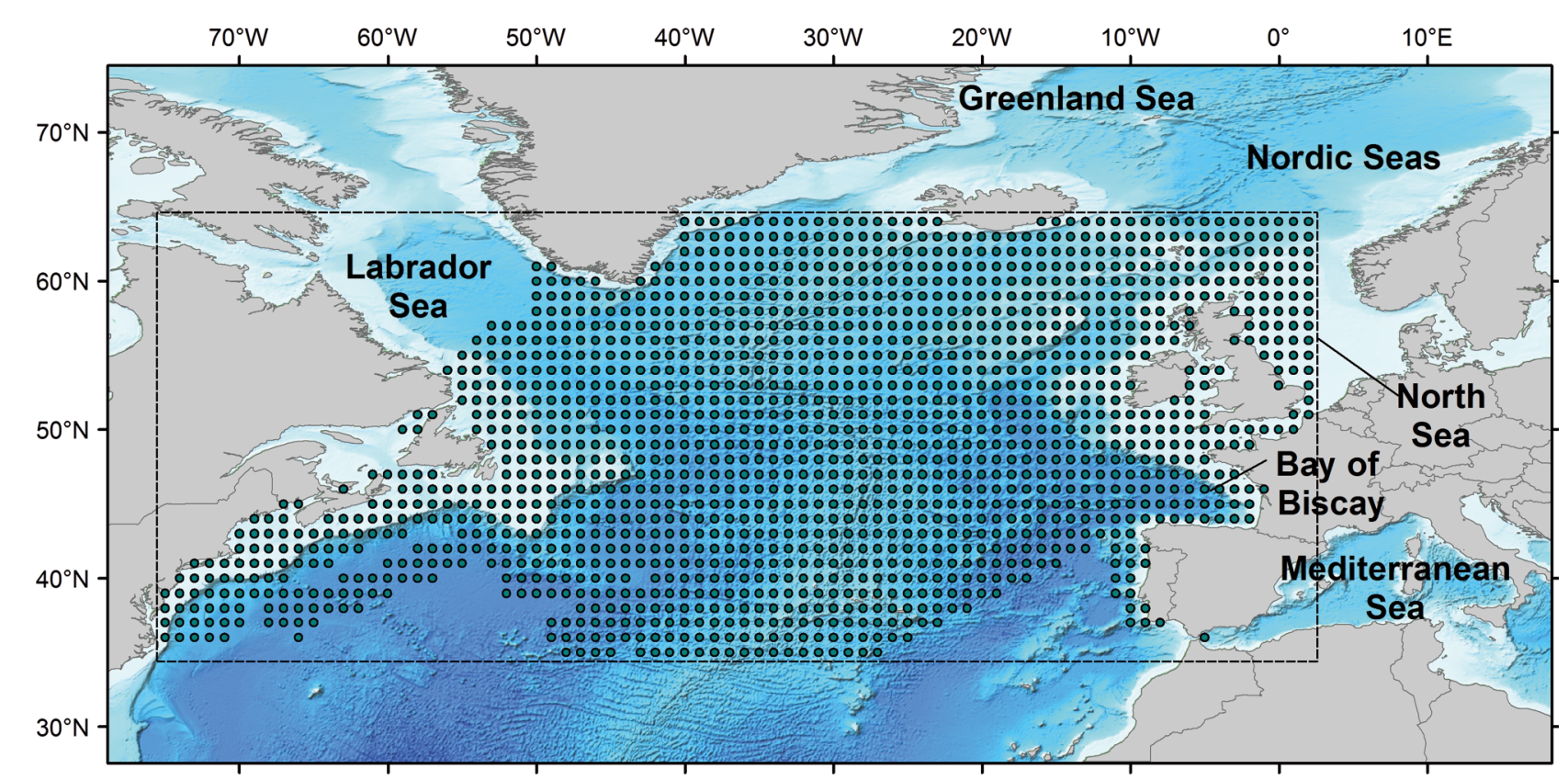

Fig. 1. The North Atlantic Basin. The domain of the studied area is 35 to $65^{\circ} \mathrm{N}$ and $75^{\circ} \mathrm{W}$ to $2^{\circ} \mathrm{E}$. Source of bathymetry: ETOPO1, NOAA, Amante and Eakins (2009). Dots represent continuous plankton recorder (CPR) sampling points of Calanus finmarchicus, C. helgolandicus, C. glacialis and C. hyperboreus in the 1970-2004 period

cies and to predict their probability of occurrence over the North Atlantic Ocean: sea surface temperature (SST), sea surface salinity (SSS), bathymetry, oxygen, $\mathrm{pH}$, sea surface phytoplankton biomass (Pc) and mixed layer depth (MLD). SST and SSS (salinity especially in coastal environments) are essential factors because of their recognized influence on spatial distribution of Calanus spp. (Mauchline 1998, Helaouët \& Beaugrand 2009, Helaouët et al. 2011, Reygondeau \& Beaugrand 2011). Bathymetry was selected because it has been suggested that it influences the distribution of some copepod species in regions such as the southern North Sea (Reygondeau \& Beaugrand 2011). Phytoplankton is an important food source for Calanus spp. that dominates zooplankton biomass in the North Atlantic (Irigoien 2004, Møller et al. 2012, Melle et al. 2014). MLD is an important parameter for phytoplankton production and controls the spatial distribution of many plankton species (Longhurst 2007). Oceanic $\mathrm{pH}$ influences calcifying organisms such as coccolithophorids, foraminifers, corals and pteropods (Orr et al. 2005, Kroeker et al. 2010).

$\mathrm{SST}$, SSS, Pc, oxygen and $\mathrm{pH}$ data were extracted from a 1960-2004 hindcast of an implementation of the NEMO-ERSEM model (a coupled hydrodynamic marine ecosystem model focusing on the ocean biogeochemistry and lower trophic level) forced with atmospheric reanalysis data from the Drakkar Forcing Set 4 (DFS4) composite of National Centers for Envi- ronmental Predictions (NCEP) and European Centre for Medium-Range Weather Forecasts (ECMWF) fields. MLD data were obtained from the Center for Marine and Atmospheric Sciences (ZMAW, Hamburg) and used as a proxy of water column stability. MLDs were obtained from vertical profiles of temperature and salinity (de Boyer Montégut et al. 2004), using the classical density criterion of 0.125 (Levitus 1983). Bathymetry was extracted from ETOPO1 global model ( 1 arc-minute global relief model of Earth's surface, NOAA). Data were organized in $1^{\circ}$ longitude and $1^{\circ}$ latitude grid resolution available for every month of the period 1970-2004.

\section{Biological data}

Data on the abundance (mean density ind. $\mathrm{m}^{-3}$ ) of 4 species (Calanus finmarchicus, C. glacialis, C. helgolandicus and C. hyperboreus) were obtained from the CPR database. The CPR survey is an upper-layer plankton monitoring programme that has regularly collected samples, at monthly intervals, in the North Atlantic and adjacent seas since 1946 (Warner \& Hays 1994). The number of records collected for the 4 Calanus spp. from the CPR survey during the 1970-2004 period is shown in Fig. A1 in the Appendix.

These calanoids are key species in subarctic (C. finmarchicus) and temperate shelf-edge (C. helgolandi- 
cus) regions of the North Atlantic Ocean (Bonnet et al. 2005, Speirs et al. 2005). C. helgolandicus is considered to be a pseudo-oceanic species, i.e. a species that can be found in oceanic and neritic waters, but it is mostly abundant above the shelf edge (Beaugrand et al. 2002b). C. glacialis and C. hyperboreus are Arctic species, while $C$. finmarchicus is a subarctic species that overlaps in size range with $C$. helgolandicus. C. hyperboreus is the largest among them.

In order to have a better representation of the copepod community at North Atlantic Basin scale, data on another 10 copepod species (ind. $\mathrm{m}^{-3}$ ) (Candacia armata, Centropages typicus, Centropages hamatus, Metridia lucens, Paraeuchaeta norvegica, Paraeuchaeta hebes, Pleuromamma borealis, Pleuromamma robusta, Pseudocalanus elongatus and Temora longicornis) were downloaded from the $\mathrm{Na}$ tional Marine Fisheries Service NMFS-COPEPOD global plankton database (www.st.nmfs.noaa.gov/ copepod/data/sahfosatl/index.html) between 1995 and 1999. It is also based on CPR survey and it represents one-third of the CPR records collected in the same region. Those species were selected as they were the most abundant copepod taxa identified at species level (with more than 100 occurrences in the data set). The selected 14 species represent $49.3 \%$ of the total occurrences sampled in the community, hence, well representing the overall community in terms of abundance. All CPR data used in the present study were gridded within 35 to $65^{\circ} \mathrm{N}$ and $-75^{\circ} \mathrm{W}$ to $2^{\circ} \mathrm{E}$ at 1 by $1^{\circ}$ spatial resolution using the inversedistance interpolation method, and analysed monthly.

\section{Habitat modelling}

We generated models based upon the prominent climate drivers for the most abundant 14 copepod species in the study area. First, model selection and validation was evaluated for 4 species (Calanus finmarchicus, C. glacialis, C. helgolandicus and C. hyperboreus) using the entire time series from 1970 to 2004. In particular, we compared GAMs with other habitat model algorithms (MD and MaxEnt), and validated the model using randomly independent data sets and comparing cold (1970-1986) with warm (1987-2004) climate regimes. That way we assessed the capacity of the model to be extrapolated to future climate. Second, we built habitat models on the other set of copepod species (10 species) in the same way as we did for the main 4 Calanus spp. using data from the 1995-1999 period. Thus, we built habitat models of 14 species to (1) evaluate the impacts of future climate change on community structure in the 2080-2099 period compared to present conditions (2001-2020), (2) quantify the poleward shift of species distribution, and (3) analyse phenological changes of the species in the North Atlantic Ocean at community level, with model outputs corresponding to the IPCC Special Report on Emissions Scenarios A1B global warming scenario (IPCC 2007).

Species distribution models assume that observations represent a species at equilibrium with its environment. Here, GAMs (Hastie \& Tibshirani 1990, Wood 2006) were used to model occurrences for each of the 4 Calanus spp. as a function of environmental factors (SST, SSS, MLD, pH and bathymetry) and potential food resource $(\mathrm{Pc})$. The strength of GAMs is due to their capacity to deal with highly non-linear relationships between the response and the set of explanatory variables, allowing asymmetrical unimodal distributions, since interaction between species and extreme environmental gradients may cause skewed responses (Oksanen \& Minchin 2002). GAMs also enable us to model the seasonal response of the species. A GAM using the binomial error distribution and logit function of the mgcv package in R (Wood 2006) was used to relate copepod presence-absence data and the explanatory environmental variables, following Chust et al. (2014a). The CPR data set used here includes 112161 samples across the spatial domain and irregularly distributed at yearly and monthly intervals.

Prior to model building, we tested for collinearity between explanatory variables by calculating variance inflation factors (VIF) with the AED package in $\mathrm{R}$ (Zuur et al. 2009). We excluded any variable that had a VIF $>3$, and then recalculated VIF for the remaining variables. We iterated this process until all variables had a VIF $<3$. The variable most often thrown out was oxygen, which highly correlated with temperature, thus we excluded it from the subsequent analysis.

We built and compared different GAMs for each species to find the optimal set of explanatory variables. Variable importance was assessed first by removing variables that were not statistically significant and second, by adding and removing terms and noting the change in deviance or gain (>1\%) in a forward stepwise procedure. For environmental variables, the degree of smoothness of model terms was restricted from 3 to 5 in order to assume a unimodal, ecologically meaningful niche model sensu Hutchinson (1957), but allowing asymmetry. After characterizing the ecological niche of each species, the environmental space was projected into geographical space and the probability of occurrence of Calanus spp. was calculated. 
To prevent overfitting, we first restricted the degrees of smoothness to ecologically interpretable responses according to niche theory; second we analysed the response of species occurrence to each environmental predictor; and third we used cross-validation methods to evaluate the reliability of the models (see next section)

\section{GAM vs. MD and MaxEnt}

GAM has been also compared with other 2 habitat models (MaxEnt and MD algorithm) in order to assess its performance. Both MaxEnt and MD algorithm are ecological niche models using presence-only species records, although they can use absences to model validation. They are implemented in the dismo $\mathrm{R}$ package (Hijmans et al. 2013), which is specially designed to model species distributions that do not migrate or shift during seasonal cycle, since it uses static environmental layers. Contrary to MD algorithm and MaxEnt habitat model techniques, GAM presents the advantage to model the seasonal response of the species resulting in a more 'dynamic' habitat modelling technique. Hence, only for the purpose of comparing performances of GAM with MaxEnt and MD algorithms, we reduced the data set into a unique spatial layer by accumulating occurrences of all years and months. The MD algorithm technique for a given point expresses the distance between this point and the species optimum in the ecological space (Farber \& Kadmon 2003, Calenge et al. 2008, Nogués-Bravo et al. 2008, Etherington et al. 2009). MaxEnt uses the principle of maximum entropy to estimate a set of functions that relate environmental variables and habitat suitability in order to approximate the niche and potential geographic distribution of the species (Phillips et al. 2006). MaxEnt model minimizes the relative entropy between 2 probability densities (presence data and the landscape data) defined in a covariate space (Elith \& Leathwick 2009, Elith et al. 2011). Although MaxEnt has been widely used in terrestrial species (e.g. Graham \& Hijmans 2006, Monterroso et al. 2009, Young et al. 2009, Yates et al. 2010), applications in pelagic species are still scarce.

\section{Model validation}

The 3 models used were validated using independent data sets for model building and model validation (Burnham \& Anderson 2002). We validated the models in 2 ways: (1) $k$-fold random resampling, and (2) temporal cross-validation. In the first procedure, the data is first partitioned into $k$ equally sized segments or folds. Subsequently, $k$ iterations of training and validation are performed so that within each iteration a different fold of the data is held-out for validation while the remaining $k-1$ folds are used for model fitting (Hijmans 2012). We used $k=5$, hence, $80 \%$ of the CPR observations were used for model building, and the other $20 \%$ (i.e. independent) for model validation in an iterative procedure that was repeated 5 times. Hold-out validation avoids the overlap between training data and test data, yielding a more accurate estimate for the generalization performance of the algorithm. The comparison between the accuracy (the proportion of true results) of the model (all observations) and that of cross-validated results also permits the detection of model overfitting, which reduce the usefulness of such models for extrapolation.

Second, the North Atlantic regime shift in the 1980s (Reid et al. 2001, Beaugrand 2004, deYoung et al. 2004) was taken into account to perform a temporal cross-validation of the models (i.e. the second procedure of model validation). A wide range of studies have investigated the North Atlantic and North Sea climate decadal fluctuations that affect phytoplankton (Edwards et al. 2001, Reid et al. 2001, Beaugrand \& Reid 2003), zooplankton (Beaugrand et al. 2002a, Beaugrand 2003, 2004) and fish populations (Alheit \& Hagen 1997, Reid et al. 2001). To this end, we performed a Wilcoxon rank sum test (Wilcoxon 1945) between a cold period from 1970 to 1986 (mean SST: $11.64 \pm \mathrm{SE} 0.12^{\circ} \mathrm{C}$ ) and a warm period from 1987 to 2004 (mean SST: $12.10 \pm \mathrm{SE} 0.26^{\circ} \mathrm{C}$ ) and defined in our time series 2 different climatic regimes $(\mathrm{p}<$ 0.0001) (Fig. 2). Subsequently, we built the models and compared the 4 Calanus spp. between cold (1970-1986) and warm (1987-2004) periods. We tested the habitat model predictive capacity validating the cold period into the warm period and vice versa, using the area under the receiver operating

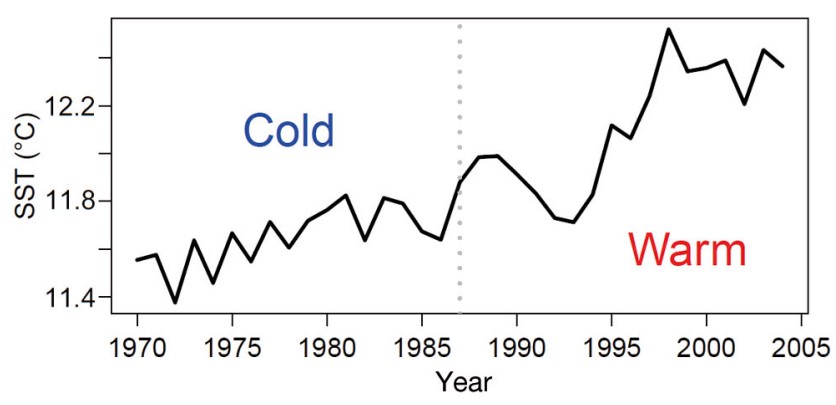

Fig. 2. Mean SST time series. Cold (1970-1896) and warm (1987-2004) periods are indicated 
characteristic curve (AUC) (Hanley \& McNeil 1982, Raes \& ter Steege 2007), and confusion matrix accuracy assessment indices (VanDerWal et al. 2011) (see 'Model evaluation' below). This approach enabled us not only to explore the model behaviour for different climates but also to see to what degree of reliability we can project the model to future warmer climate conditions. The temporal cross-validation was undertaken only to the 4 Calanus spp., since the NMFSCOPEPOD time series (1995-1999) including the other set of 10 copepod species is too short.

\section{Model evaluation}

We assessed the predictive performance of the overall model and the held-out folds using the AUC, a measure of the ability of the predictions to discriminate presence from absence, and accuracy indices derived from confusion matrix. To this end, the species presence modelled probability was converted to either presence or absence using probability thresholds following 2 criteria: sensitivity (true predicted presences) $=$ specificity (true predicted absences), and maximization of sensitivity plus specificity, as reported in Jiménez-Valverde \& Lobo (2007). Thus, the cases above this threshold are assigned to presences, and below to absences. Given the threshold value, a confusion matrix was calculated yielding outputs of correctly identified records of presence and absence to have an overall accuracy estimate of model performance. Overall accuracy ranges from 0 to $100 \%$ and AUC values from 0.5 (random sorting) to 1 (perfect discrimination). Accuracy is a good indicator of model performance since it is the proportion of true results, either true positive or true negative, in a population.

\section{Climatic scenario for the 21st century}

In order to assess the copepod response to climate change, selected habitat models were projected to future conditions and thresholds were applied to the resulting probability maps. We used modelled environmental predictors (SST, SSS and Pc) from the DKRZ-CERA database (http://cera-www.dkrz.de) at IPCC A1B scenario for the 2001-2099 period. More in detail, we used the Hamburg Ocean Carbon Cycle (HAMOCC) model for the phytoplankton, and the Max Planck Institute's Ocean General Circulation Model (MPIOM) (Jungclaus et al. 2013) for the physical set up. HAMOCC, embedded into MPIOM, sim- ulates the oceanic cycles of carbon and other biogeochemical elements (Ilyina et al. 2013). Technical details of the ocean model MPIOM can be found in Marsland et al. (2003).

\section{Assessing impacts of climate change on copepods}

The impacts of climate change on copepods were assessed by estimating latitudinal shifts of each species, phenological changes and spatial patterns of biodiversity indices.

The latitudinal shift $(\mathrm{km})$ of the species was calculated by comparing the geographic centre of gravity of its suitable area for present (2001-2020) and future scenarios (2080-2099). The centre of gravity is defined as the mean geographic location of a population (Woillez et al. 2009). Gravity centres of habitat models showing well-separated east to west population patches (C. armata, C. hamatus and P. hebes) were calculated separately and then averaged. We assumed unlimited copepod dispersal to estimate the extent of gain or loss of suitable space from present to future modelled conditions.

We computed the changes in the seasonal cycle or phenology of Calanus spp. by analysing the difference in terms of days on the annual maxima of the copepods' probabilities of occurrence in both present and future conditions. The timing of the peak was determined as the date when the modelled species occurrences reached the annual maximum. Monthly mean species occurrences were used to build a GAM fitted function (with a Gaussian link and cyclic cubic regression spline) to predict the seasonal peaks, and to quantify the phenological shifts in days.

We carried out a seasonal quantitative analysis only on C. hyperboreus and C. finmarchicus since their predicted phenological patterns matched relatively well with observed ones. We did not perform any phenology analysis in the NMFS-COPEPOD set of species either, due to time series shortness.

Changes in local biodiversity were assessed in terms of species turnover, colonization and extinction. In particular, we mapped 4 biodiversity components of change: (1) stability, i.e. the number of species that were present or absent at both present and future scenarios at each pixel ${ }_{i}(2)$ extinction, i.e. the number of species that were present at present and were absent in the future; (3) colonization, i.e. the number of species that were absent at present and present in the future; and (4) turnover, i.e. the number of species that suffer either colonization or extinction. 
Species assemblages were categorized following Beaugrand et al. (2009) in 2 main groups: (1) the 'cold-water species assemblage', including the cold- temperate mixed water (Pleuromamma robusta), subarctic (Calanus finmarchicus) and Arctic (Calanus hyperboreus and Calanus glacialis) species assemblages, and (2) the 'warm-water species assemblage', including the warm-temperate oceanic and pseudo-oceanic (Pleuromamma borealis, Paraeuchaeta norvegica, Metridia lucens and Paraeuchaeta hebes), the temperate pseudooceanic (Centropages typicus, Candacia armata and Calanus helgolandicus) and continental shelf (Pseudocalanus elongatus, Temora longicornis and Centropages typicus). This simplified way of proceeding enabled us to understand which set of species was more affected by environmental change.

\section{RESULTS}

\section{Future environmental changes}

MPIOM SST model projections forecasted an average $\left( \pm \mathrm{SD}\right.$ ) increase of $1.54 \pm 0.35^{\circ} \mathrm{C}$ (Wilcoxon rank sum test, $\mathrm{p}<0.0001$ ) from 2001-2020 to 2080-2099 in the North Atlantic study area (Fig. 3). Our spatial examination of changes in SST reveals regional differences. For instance, SST increased by 4 to $6^{\circ} \mathrm{C}$ in areas of the Gulf Stream extension and the Newfoundland continental shelf, south of the Oceanic Polar Front (i.e. $60-45^{\circ} \mathrm{W}$ and $43-48^{\circ} \mathrm{N}$ ). On the other hand, in some areas of the subarctic region south of the Labrador Current in the North Atlantic Gyre (i.e. $40-30^{\circ} \mathrm{W}$ and $55-60^{\circ} \mathrm{N}$ ), SST is expected to decrease by up to $1^{\circ} \mathrm{C}$.

The HAMOCC biogeochemical model projects a general Pc decrease by the end of century in the North Atlantic. Results showed a clear east to west asymmetry on Pc changes, with strong negative differences $\left(-30\right.$ to $-20 \mathrm{mg} \mathrm{C} \mathrm{m}{ }^{-3}$ ) along the east of the Oceanic Polar Front, from the subarctic region south of Iceland down to the Bay of Biscay and the Southern European shelf edge (i.e. $25-5^{\circ} \mathrm{W}$ and $\left.38-60^{\circ} \mathrm{N}\right)$. In turn, a slight increase in Pc $\left(0-10 \mathrm{mg} \mathrm{C} \mathrm{m}^{-3}\right)$ is projected along the Flemish Cup area and extending thought the Oceanic Polar Front (i.e. $50-40^{\circ} \mathrm{W}$ and $43-50^{\circ} \mathrm{N}$ ) (Fig. 3).
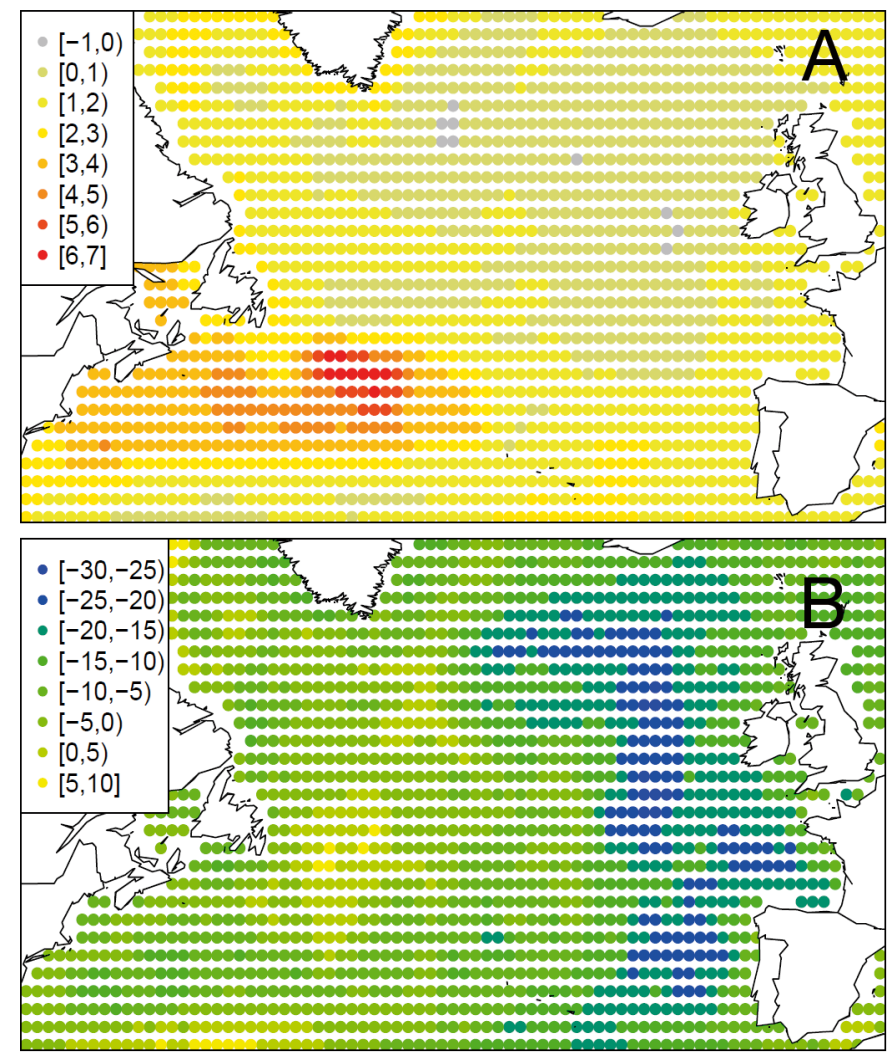

Fig. 3. Difference models of (A) sea surface temperature $\left({ }^{\circ} \mathrm{C}\right)$ and (B) surface phytoplankton biomass $\left(\mathrm{mg} \mathrm{m}^{-3}\right)$ for present (2001-2020) and future (2080-2099) periods

\section{GAM habitat models}

We evaluated the response of the Calanus spp. to each explanatory variable individually using GAMs (Table 1). SST was the most important environmental driver in the Calanus ssp. environmental space, followed by SSS, depth and Pc. Oceanic pH and MLD explained less deviance of species occurrence, although $\mathrm{pH}$ was considered in the model selection as it accounted for more than $1 \%$ of deviance for all models.

Table 1. Generalized additive model. Explained deviance (\%) of Calanus spp. occurrence in the North Atlantic Basin according to each environmental factor. SST: sea surface temperature, SSS: sea surface salinity, Pc: surface phytoplanktion biomass, MLD: mixed layer depth

\begin{tabular}{|lcccccccc|}
\hline & SST & SSS & $\mathrm{O}_{2}$ & pH & Pc & Chl a & MLD & Depth \\
\hline C. finmarchicus & 14.2 & 15.1 & 18.9 & 4.4 & 6.2 & 6.1 & 0.6 & 5.5 \\
C. helgolandicus & 11.3 & 5.4 & 3.4 & 1.8 & 0.4 & 0.3 & 2.8 & 14.1 \\
C. glacialis & 29.6 & 25.5 & 25.9 & 1.9 & 4.2 & 3.2 & 0.7 & 0.1 \\
C. hyperboreus & 21.5 & 13.0 & 30.8 & 6.6 & 16.5 & 12.0 & 0.3 & 4.8 \\
\hline
\end{tabular}



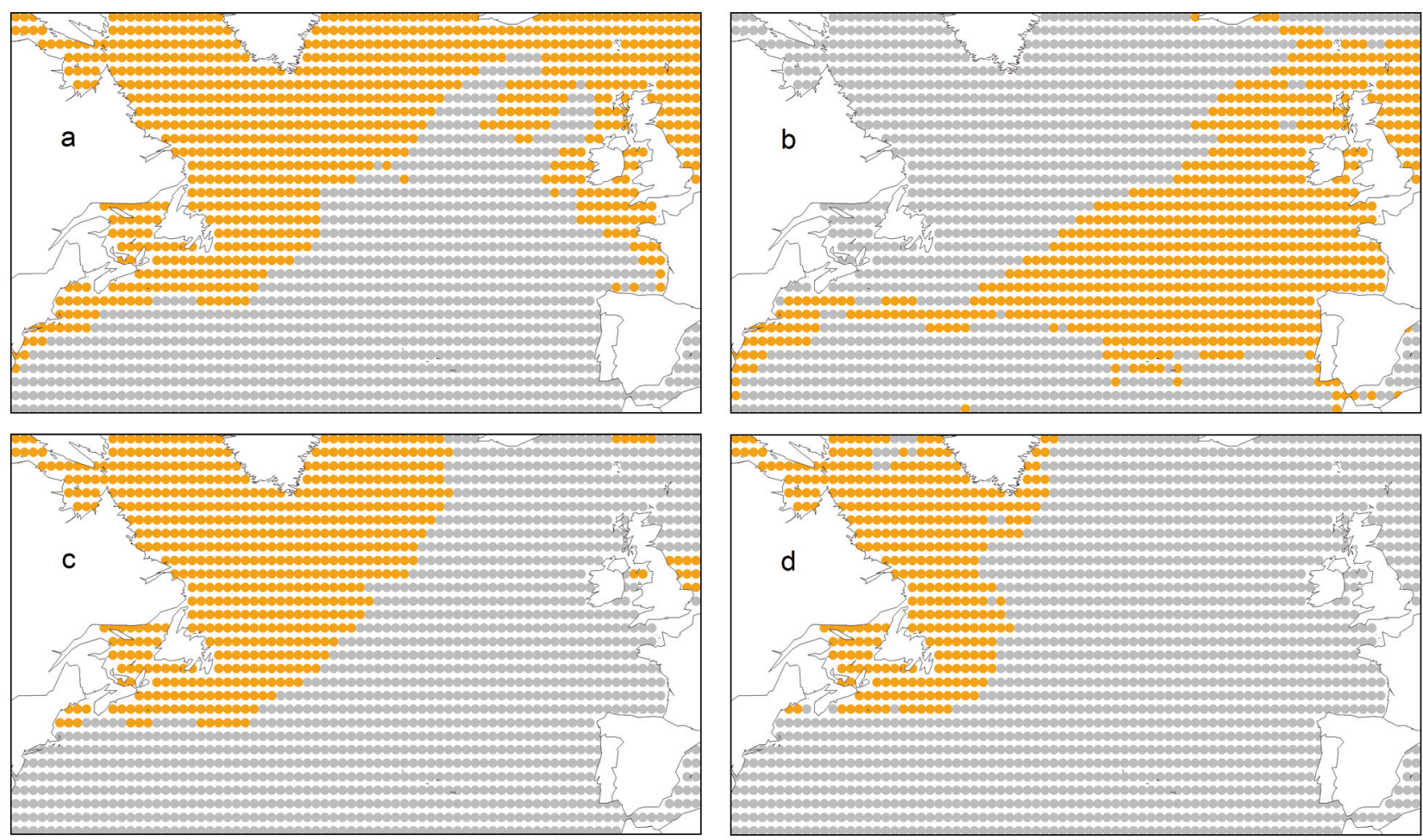

Fig. 4. Occurrence models of Calanus spp. in the 1970-2004 period. Orange: presence; grey: absence. (A) C. finmarchicus,

(B) C. helgolandicus, (C) C. glacialis and (D) C. hyperboreus

Habitat suitability models were constructed for the 4 Calanus spp. (Fig. 4). All the subsequent environmental variables, i.e. SST, SSS, depth, $\mathrm{pH}$ and Pc, were included in all models except for C. glacialis (without $\mathrm{pH}$ and $\mathrm{Pc}$ ) and for C. helgolandicus (without Pc).

The random cross-validation of models is shown in Table 2. The habitat models in the 4 Calanus spp. showed a slight drop in the accuracy measure if we compare all observations $(74-85 \%)$ vs. the $k$-fold cross-validation $(69-85 \%)$; this is owing to a slight signal of model overfitting. Here, C. helgolandicus showed low overall deviance explained $(25.4 \%)$ in the habitat suitability models, whilst the other species deviance explained was higher: C. finmarchicus (46.9\%), C. glacialis (34.1\%) and C. hyperboreus (42.3\%).

The temporal cross-validation enabled us to assess the model reliability to be extrapolated to different climates. Results have shown that model accuracy is relatively good (75-84\%) for the models built in the cold period and extrapolated and validated in the warm period (Table 3). Therefore, species models can be used to be projected in future climate simulations with relative confidence.

GAM habitat models for the non-Calanus spp. set of copepods (Table 4) showed a slightly lower accuracy $(64-74 \%)$ than for the 4 Calanus spp. Moder- ate deviance explained was found in Centropages typicus $(25.4 \%)$, Centropages hamatus (28.7\%), Paraeuchaeta norvegica $(27.5 \%)$, Paraeuchaeta hebes $(35.4 \%)$ and Temora longicornis $(24.9 \%)$. For the remaining set of species the deviance explained was lower $(17.5-7.7 \%)$, as were the accuracy values. The difference in the accuracy values of the model using all the observations (76-63\%) and those crossvalidated (53-57\%) indicated a slight overfitting in these latter models (Table 4).

\section{Model comparison: GAM vs. MD and MaxEnt}

MaxEnt ranked first in terms of model accuracy or performance, followed by GAM and MD, with similar values for C. glacialis and C. helgolandicus but higher values for GAM in C. hyperboreus and C. finmarchicus (Fig. 5).

However, we have shown that GAM, which is a presence-absence-based model, predicts correctly the potential distribution of C. glacialis along the Labrador Sea, Newfoundland shelf and the Davis Strait, where it is abundant according to Head et al. (2003) and Pomerleau et al. (2014), whilst both MaxEnt and MD predicted absence (Fig. A2 in the Appendix). 
Table 2. Evaluation of generalized additive models (yearly accumulated) with $k$-fold cross-validation. Variables entered: sea surface temperature (SST), sea surface salinity (SSS), bathymetry, surface phytoplankton ( $\mathrm{Pc}$ ) and $\mathrm{pH}$. Thresholds for conversion of probability of species presence to either presence or absence in model validation: 0.08 (Calanus hyperboreus), 0.11 (C. glacialis), 0.48 ( $C$. helgolandicus) and 0.63 (C. finmarchicus). Values in the AUC column refer to model with all observations/mean $k$-fold cross-validation. Values in the accuracy column refer to model with all observations/mean $k$-fold cross-validation (\%). edf: estimated degrees of freedom. All $\mathrm{p}<0.001$; na: not applicable

\begin{tabular}{|c|c|c|c|c|}
\hline $\begin{array}{l}\text { Variables } \\
\text { selected }\end{array}$ & edf & $\begin{array}{c}\text { Overall deviance } \\
\text { explained }(\%)\end{array}$ & AUC & Accuracy \\
\hline \multicolumn{5}{|c|}{ C. hyperboreus } \\
\hline SST & 1.99 & & & \\
\hline SSS & 1.00 & & & \\
\hline Depth & 2.17 & & & \\
\hline $\mathrm{pH}$ & 1.96 & & & \\
\hline \multirow[t]{2}{*}{$\mathrm{PC}_{\mathrm{C}}$} & na & & & \\
\hline & & 42.3 & $0.845 / 0.698$ & $85.34 / 69.84$ \\
\hline \multicolumn{5}{|c|}{ C. glacialis } \\
\hline SST & 1.95 & & & \\
\hline SSS & 2.88 & & & \\
\hline \multirow[t]{2}{*}{ Depth } & 1.00 & & & \\
\hline & & 34.1 & $0.816 / 0.642$ & $81.90 / 71.25$ \\
\hline \multicolumn{5}{|c|}{ C. helgolandicus } \\
\hline $\mathrm{SST}$ & 1.99 & & & \\
\hline SSS & 2.99 & & & \\
\hline Depth & 2.85 & & & \\
\hline \multirow[t]{2}{*}{$\mathrm{pH}$} & 1.97 & & & \\
\hline & & 25.4 & $0.749 / 0.754$ & $74.94 / 75.40$ \\
\hline \multicolumn{5}{|c|}{ C. finmarchicus } \\
\hline SST & 1.97 & & & \\
\hline SSS & 2.74 & & & \\
\hline Depth & 2.88 & & & \\
\hline $\mathrm{pH}$ & 1.83 & & & \\
\hline \multirow[t]{2}{*}{$\mathrm{PC}_{\mathrm{C}}$} & na & & & \\
\hline & & 46.9 & $0.852 / 0.851$ & $85.19 / 85.13$ \\
\hline
\end{tabular}

\section{Latitudinal shift under climate change scenarios}

Despite the different thermal window of each of the 14 species analysed, all centres of gravity have been located in the central temperate part $\left(45-55^{\circ} \mathrm{N}\right)$ of the North Atlantic Ocean, both at present and future periods (Figs. $6 \& 7$ ). Distribution centroids of most of our studied species were projected to shift poleward under climate change (Table 5). All copepod assemblages showed a northward shift of $0.1-$ $13.5 \mathrm{~km}$ per decade for the shelf-sea association species (Paraeuchaeta hebes, Paraeuchaeta norvegica and Temora longicornis), of 3.7-11.3 km per decade in the Arctic and subarctic association (Calanus hyperboreus, Calanus glacialis and Calanus finmarchicus) and of 1.9-17.8 km for temperate or warm-water species association (Metridia lucens, Pleuromamma ro- busta, Pleuromamma borealis, Calanus helgolandicus, Centropages typicus and Candacia armata). A southward migration in centre of gravity of ca. 11-15.4 km per decade was found in other shelf-sea and temperate association species (Pseudocalanus elongatus and Centropages hamatus). On average, a poleward community shift of $8.7 \mathrm{~km}$ per decade was predicted, with an important species range variation $(-15-18 \mathrm{~km}$ per decade). Poleward shifts of the warm-temperate copepod assemblage were more important than the range contraction of the subarctic and Arctic species assemblage. These shift rates were generally associated with a reduction located at the southern edge of the species spatial distribution. Such changes could be linked to regional SST warming.

At species level, projections revealed a poleward shift with a slight contraction of the southern limit of habitat suitability distribution of the C. finmarchicus, C. glacialis and C. hyperboreus, and a shelfward constriction of $C$. helgolandicus, disappearing from oceanic warm waters south of the Oceanic Polar Front (Fig. 7).

The average northward retreat is more clearly seen in C. finmarchicus, C. glacialis and C. hyperboreus, with local projected shifts of up to $25-70 \mathrm{~km}$ per decade in the southern limits of their distribution. We observed that the probabilities of $C$. finmarchicus occupying large areas of the Labrador Sea and Buffin Bay will increase considerably by the end of the century, as well as in the northern North Atlantic Gyre and the Irminger Current. The C. hyperboreus and C. glacialis map showed a similar pattern: their distribution will be mainly reduced northwestward, from Labrador to Newfoundland and the Greenland Sea. The ecological niche of C. finmarchicus and C. glacialis will suffer an important habitat reduction in the warm-temperate waters of the central North Atlantic around the Gulf Stream and the North Atlantic Drift provinces, with potential local extinctions. A mean poleward migration of C. glacialis of $11.3 \mathrm{~km}$ per decade is estimated, much more acute than in $C$. finmarchicus (3.7 km per decade). Its habitat suitability will probably respond to future warmer SST shifting northward to the Irminger Current, Faroe-Shetland Channel and Norwegian Trench (Figs. 6 \& 7). A noticeable habitat gain in C. glacialis is predicted in the northern subarctic region, south of Iceland and the northern European shelf edge; this has contributed to a higher poleward shift of the centroid. Future projections of C. hyperboreus habitat suitability have also indicated a reduction in the southwestern edge of its spatial distribution where the species might face extinction. It will have a straightforward 
Table 3. Evaluation of generalized additive models (yearly accumulated) with temporal cross-validation. Models built in cold period validated in warm period. Variables entered: sea surface temperature (SST), sea surface salinity (SSS), bathymetry, surface phytoplankton biomass (Pc) and $\mathrm{pH}$. Values in the AUC column refer to model with all observations/mean $k$-fold cross-validation. Values in the accuracy column refer to model with all observations/mean $k$-fold cross-validation (\%). edf: estimated degrees of freedom; na: not applicable

\begin{tabular}{|c|c|c|c|c|c|}
\hline $\begin{array}{l}\text { Variables } \\
\text { selected }\end{array}$ & edf & $\mathrm{p}$-value & $\begin{array}{c}\text { Overall } \\
\text { explained } \\
\text { deviance (\%) }\end{array}$ & AUC & Accuracy \\
\hline \multicolumn{6}{|c|}{ Calanus hyperboreus } \\
\hline SST & 1.99 & $<0.001$ & & & \\
\hline SSS & 1.00 & $<0.001$ & & & \\
\hline Depth & 2.90 & $<0.001$ & & & \\
\hline $\mathrm{pH}$ & 1.98 & $<0.001$ & & & \\
\hline \multirow[t]{2}{*}{$\mathrm{PC}$} & na & na & & & \\
\hline & & & 48.1 & $0.845 / 0.807$ & $85.34 / 80.80$ \\
\hline \multicolumn{6}{|c|}{ C. glacialis } \\
\hline SST & 1.73 & $<0.001$ & & & \\
\hline SSS & 2.84 & $<0.001$ & & & \\
\hline \multirow[t]{2}{*}{ Depth } & 1 & 0.0143 & & & \\
\hline & & & 30.7 & $0.816 / 0.691$ & $81.90 / 74.33$ \\
\hline \multicolumn{6}{|c|}{ C. helgolandicus } \\
\hline SST & 1.99 & $<0.001$ & & & \\
\hline SSS & 2.99 & $<0.001$ & & & \\
\hline Depth & 2.95 & $<0.001$ & & & \\
\hline \multirow[t]{2}{*}{$\mathrm{pH}$} & 1.98 & $<0.001$ & & & \\
\hline & & & 27.3 & $0.749 / 0.745$ & $74.94 / 74.83$ \\
\hline \multicolumn{6}{|c|}{ C. finmarchicus } \\
\hline SST & 1.95 & $<0.001$ & & & \\
\hline SSS & 2.87 & $<0.001$ & & & \\
\hline Depth & 2.80 & $<0.001$ & & & \\
\hline $\mathrm{pH}$ & 2 & $<0.001$ & & & \\
\hline \multirow[t]{2}{*}{ Pc } & na & na & & & \\
\hline & & & 45.2 & $0.852 / 0.857$ & $85.19 / 85.73$ \\
\hline
\end{tabular}

gica might face local extinction along the southern limits of its distribution. The overall suitable habitat is therefore expected to increase in these temperate-warm and shelf species assemblages. The habitat suitability of other sets of studied species did not show any latitudinal shift, but rather an east to west asymmetry: Centropages hamatus might colonize the Bay of Biscay and the southern European shelf edges, and Paraeuchaeta hebes would become extinct from the North Sea and the southern European shelf edge. The model explained deviance for $M$. lucens is too low ( $7.7 \%$ ) to draw conclusions on its habitat suitability change.

The warm-temperate and continental shelf sets of species assemblages have shown the highest local northward shifts. Southern temperate regions are becoming warmer and are expected to provide suitable habitat for the warm-temperate and temperate pseudo-oceanic species assemblages. Thus, overall, warm species assemblages will respond faster to climatic change and cold species assemblages will retract their core distribution northward at a slower pace. climatic response with a poleward mean latitudinal shift of ca. $8 \mathrm{~km}$ per decade. The species might disappear also from the southward flow of the East Greenland Current. Our models also predicted that C. helgolandicus might disappear from the warmtemperate subtropical areas of the North Atlantic and some areas of the Bay of Biscay and southern European shelf edge, and that it will colonize the North Atlantic Drift province and the east of the Oceanic Polar Front, with a relatively high net northward movement of ca. $18 \mathrm{~km}$ per decade (Figs. $6 \& 7$ ).

Ecological niche models of warm-temperate pseudo-oceanic (Candacia armata and Centropages typicus) and continental shelf assemblages (Pseudocalanus elongatus) also project a habitat gain in the temperate North Atlantic and along the Gulf Stream and North Atlantic Current. The warm-temperate Pleuromamma borealis and the cold mixed water Pleuromamma robusta also will gain habitat in the Oceanic Polar Front and subarctic region of the North Atlantic. The temperate Paraeuchaeta norve-

\section{Phenology changes under climate change scenarios}

Our projections showed an earlier timing of predicted occurrences of the annual maxima of $12 \mathrm{~d}$ in both copepod species (C. finmarchicus annual maxima at present was 15 April and in future was 3 April; C. hyperboreus at present was 27 April and in future was 15 April) (Fig. 8).

\section{Species turnover under climate change scenarios}

Results have shown a high species turnover area (4-11 species) south of the Oceanic Polar Front (42.8-78.5\%) compared with the overall North Atlantic (ca. 10\%), covering vast areas of the centre of the North Atlantic Drift and extending up to the northern boundary of the influence of the Mediterranean water (Fig. 9A). Another moderate turnover rate (2-4 species, $21.4 \%$ ) was found in coastal zones 
Table 4. Generalized additive models for the period 1995-1999. All observation-based models vs. $k$-fold cross-validated models. Threshold for conversion of probability of species presence to either presence or absence in model validation: 0.09 (Candacia armata), 0.24 (Centropages typicus), 0.07 (Centropages hamatus), 0.35 (Metridia lucens), 0.14 (Paraeuchaeta norvegica), 0.1 (Paraeuchaeta hebes), 0.1 (Pleuromamma borealis), 0.08 (Pleuromamma robusta), 0.2 (Pseudocalanus elongatus) and 0.26 (Temora longicornis). Values in the AUC column refer to model with all observations/mean $k$-fold cross-validation. Values in the accuracy column refer to model with all observations/mean $k$-fold cross-validation (\%). edf: estimated degrees of freedom

\begin{tabular}{|c|c|c|c|c|c|}
\hline $\begin{array}{l}\text { Variables } \\
\text { selected }\end{array}$ & edf & $\mathrm{p}$-value & $\begin{array}{l}\text { Overall explained } \\
\text { deviance }(\%)\end{array}$ & AUC & Accuracy \\
\hline \multicolumn{6}{|c|}{ Candacia armata } \\
\hline SST & 1.80 & $<0.001$ & & & \\
\hline SSS & 1 & $<0.001$ & & & \\
\hline Depth & 1.79 & $<0.001$ & 15.4 & $0.738 / 0.558$ & $75.1 / 55.9$ \\
\hline \multicolumn{6}{|c|}{ Centropages typicus } \\
\hline SST & 1.002 & $<0.001$ & & & \\
\hline SSS & 1 & $<0.001$ & & & \\
\hline Depth & 2.413 & $<0.001$ & & & \\
\hline $\mathrm{pH}$ & 1.965 & $<0.001$ & 25.4 & $0.761 / 0.730$ & $76.2 / 73.0$ \\
\hline \multicolumn{6}{|c|}{ Centropages hamatus } \\
\hline SST & 1.95 & $<0.001$ & & & \\
\hline SSS & 1.96 & $<0.001$ & & & \\
\hline Depth & 2.62 & $<0.001$ & & & \\
\hline $\mathrm{pH}$ & 1.88 & $<0.001$ & 28.7 & $0.846 / 0.747$ & $80.3 / 74.7$ \\
\hline \multicolumn{6}{|c|}{ Metridia lucens } \\
\hline SST & 1.98 & $<0.001$ & & & \\
\hline SSS & 2.70 & $<0.001$ & & & \\
\hline Depth & 2.92 & $<0.001$ & & & \\
\hline $\mathrm{pH}$ & 1.89 & $<0.001$ & 7.65 & $0.637 / 0.574$ & $63.3 / 57.4$ \\
\hline \multicolumn{6}{|c|}{ Paraeuchaeta norvegica } \\
\hline SST & 1.99 & $<0.001$ & & & \\
\hline SSS & 2.71 & $<0.001$ & & & \\
\hline Depth & 2.95 & $<0.001$ & & & \\
\hline $\mathrm{pH}$ & 1.86 & $<0.001$ & 27.5 & $0.783 / 0.644$ & $78.2 / 64.4$ \\
\hline \multicolumn{6}{|c|}{ Paraeuchaeta hebes } \\
\hline SST & 1.96 & $<0.001$ & & & \\
\hline SSS & 2.88 & 0.0896 & & & \\
\hline Depth & 2.75 & $<0.001$ & & & \\
\hline $\mathrm{pH}$ & 1.44 & $<0.001$ & 35.4 & $0.854 / 0.700$ & $84.5 / 70.0$ \\
\hline SST & 1.95 & $<0.001$ & & & \\
\hline Depth & 2.59 & $<0.001$ & & & \\
\hline $\mathrm{pH}$ & 1.89 & $<0.001$ & 23.3 & $0.770 / 0.672$ & $78.3 / 67.3$ \\
\hline \multicolumn{6}{|c|}{ Pleuromamma borealis } \\
\hline SST & 1.91 & $<0.001$ & & & \\
\hline Depth & 2.29 & $<0.001$ & & & \\
\hline $\mathrm{pH}$ & 1.81 & 0.0231 & 15.7 & $0.767 / 0.530$ & $76.7 / 53.0$ \\
\hline \multicolumn{6}{|c|}{ Pleuromamma robusta } \\
\hline SST & 1.93 & $<0.001$ & & & \\
\hline Depth & 2.74 & $<0.001$ & & & \\
\hline $\mathrm{pH}$ & 1 & 0.0028 & 11.4 & $0.713 / 0.530$ & $71.3 / 52.9$ \\
\hline \multicolumn{6}{|c|}{ Pseudocalanus elongatus } \\
\hline SST & 1.35 & $<0.001$ & & & \\
\hline SSS & 2.88 & $<0.001$ & & & \\
\hline Depth & 2.49 & $<0.001$ & & & \\
\hline $\mathrm{pH}$ & 1.79 & $<0.001$ & & & \\
\hline PC & & & 17.5 & $0.723 / 0.631$ & $71.8 / 63.1$ \\
\hline \multicolumn{6}{|c|}{ Temora longicornis } \\
\hline SST & 1.00 & $<0.001$ & & & \\
\hline SSS & 1.26 & $<0.001$ & & & \\
\hline Depth & 2.61 & $<0.001$ & & & \\
\hline $\mathrm{pH}$ & 1.40 & $<0.001$ & 24.9 & $0.779 / 0.730$ & $78.1 / 73.1$ \\
\hline
\end{tabular}

of southern Bay of Biscay and in the continental shelf current. High intensity of species invasion (3-5 new species) was projected to be concentrated along the Oceanic Polar Front (Fig. 9B). Local extinctions were projected to be most common (3-6 species lost) in temperate waters of the North Atlantic, south of the Oceanic Polar Front and by the northern boundary of the influence of Mediterranean water (Fig. 9C). Areas of high turnover overlap with areas of both highest SST and Pc changes between present and future periods (Fig. 3), and also correspond relatively well with the southern edge of the cold-temperate, subarctic and Arctic species assemblage (C. hyperboreus, C. glacialis and C. finmarchicus), and the northern biogeographic boundaries of the warmtemperate species assemblage (C. armata and C. typicus) (Fig. 7).

\section{DISCUSSION}

\section{Habitat suitability models}

Habitat suitability modelling enabled us to identify 3 key environmental variables (SST, SSS and depth) that determine the present distribution of Calanus spp. SST is, in general, the environmental driver explaining most of the variance of species occurrence in the 4 Calanus spp. (especially in C. glacialis) habitat models. Previous niche-model-related works (Beaugrand et al. 2013, Chust et al. 2014a) showed similar results. It is interesting to pinpoint that models also included $\mathrm{Pc}_{\mathrm{C}}$ and $\mathrm{pH}$. Pc seems to be a controlling factor in the probability of occurrence and distribution of C. hyperboreus and C. finmarchicus, but not of C. glacialis and C. helgolandicus. Both surface phytoplankton biomass and $\mathrm{pH}$ have not been used frequently in zooplankton habitat modelling to date, since they cause only low variance of Calanus spp. occurrence, as has been shown in previous attempts 


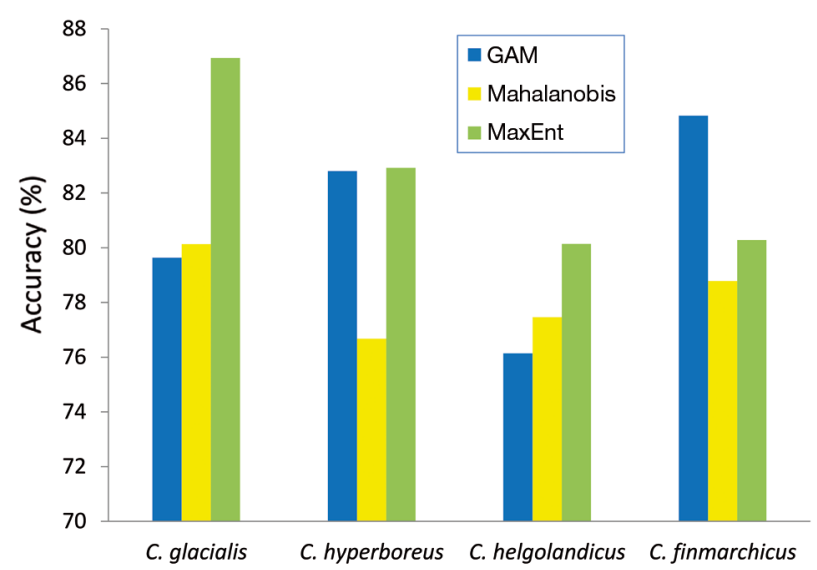

Fig. 5. Accuracy of each different model according to Calanus spp. GAM: generalized additive model

(e.g. Reygondeau \& Beaugrand 2011). This is probably because Pc represents only a part of the food available and because food is not a limiting factor above the mixed layer depth.

The MD and MaxEnt species distribution models failed in predicting the spatial distribution of C. glacialis along the Labrador Sea, Newfoundland shelf and the Davis Strait, probably because the CPR routes do not regularly cover the northern Labrador Sea area and these types of models are based only on the presence points while not accounting for absence points. Instead, GAM has proved to be a useful and accurate model to quantify the ecological niche of Calanus spp. in the North Atlantic. This conclusion is based on (1) the accuracy values of random (69-
$85 \%)$ and temporal (74-85\%) validation, (2) its flexibility to incorporate seasonal variability, and (3) its performance comparing both accuracy values and spatial distribution maps with MaxEnt and MD algorithms. The relatively good accuracy of temporal cross-validation enabled us to use confidently the GAM-based habitat models generated for Calanus spp. in the future climate simulation.

It should be noted that there are some local differences (especially south of the Oceanic Polar Front) between the GAM habitat models built with the NEMO-ERSEM model and the MPIOM-HAMOCC for the present time in the 4 Calanus spp. The latter habitat suitability models are biased, having their gravity centres located farther south. However, since we are using the same model (MPIOM-HAMOCC) to make the projections at future and present conditions, then differences in environmental covariates will stay relative and vary accordingly in time.

One of the limitations of the niche modelling approach is that in principle it does not include the effects of dispersal that can play a significant role in the distribution of plankton (Irigoien et al. 2011, Chust et al. 2013). However, it has to be taken into account that when we use field distribution data to build the model we partially include such effects, albeit in an indirect way. Some of the areas where we find a species, and therefore model as suitable niche, may actually be suitable due to transport, not because of the environmental conditions. Therefore, the model is likely to let zooplankton distribute in a wider area than its optimal niche.

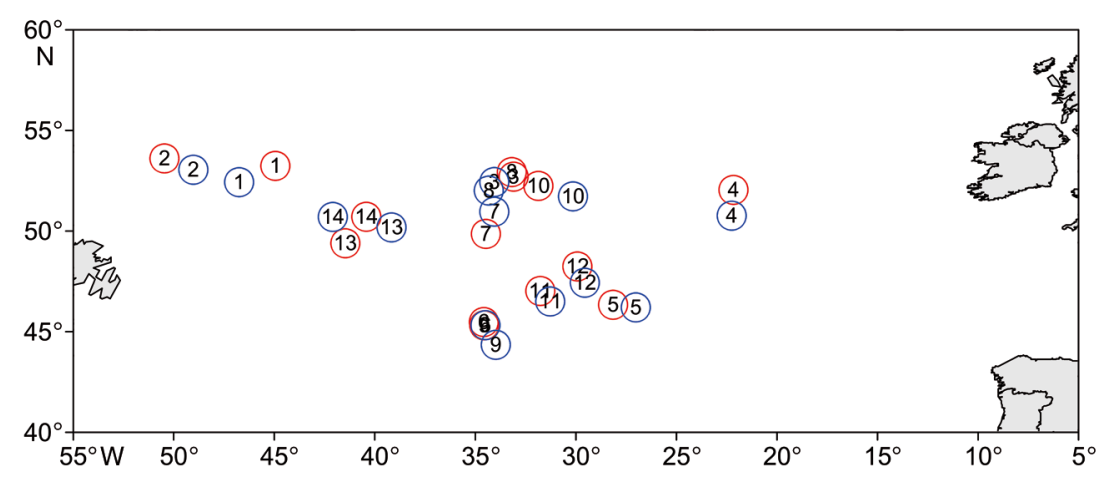

Fig. 6. Latitudinal shift of species in the North Atlantic by taking into account the gravity centre of each. Position of the gravity centre at present (2001-2020) (blue circles); position of the gravity centre for the future (2080-2099) (red circles); 1: Calanus glacialis; 2: Calanus hyperboreus; 3: Calanus finmarchicus; 4: Calanus helgolandicus; 5: Candacia armata; 6: Centropages typicus; 7: Centropages hamatus; 8: Paraeuchaeta norvegica; 9: Paraeuchaeta hebes; 10: Metridia lucens; 11: Pleuromamma borealis; 12: Pleuromamma robusta; 13: Pseudocalanus elongatus; 14: Temora longicornis

\section{Latitudinal shift}

This study showed that the Hutchinson's ecological niche of $C$. finmarchicus and that of C. helgolandicus will keep well separated in the future. This species niche separation was well described for the historic CPR data set (1942-2002) in Helaouët \& Beaugrand (2007). The modelled spatial distribution of $C$. finmarchicus showed that this species mainly occurred in areas above the Oceanic Polar Front (Dietrich 1964). It has a broader tolerance interval than its congener $C$. helgolandicus (Helaouët \& Beaugrand 2007), though it is able to cope with larger environmental variations. In fact, it co-occurs with 

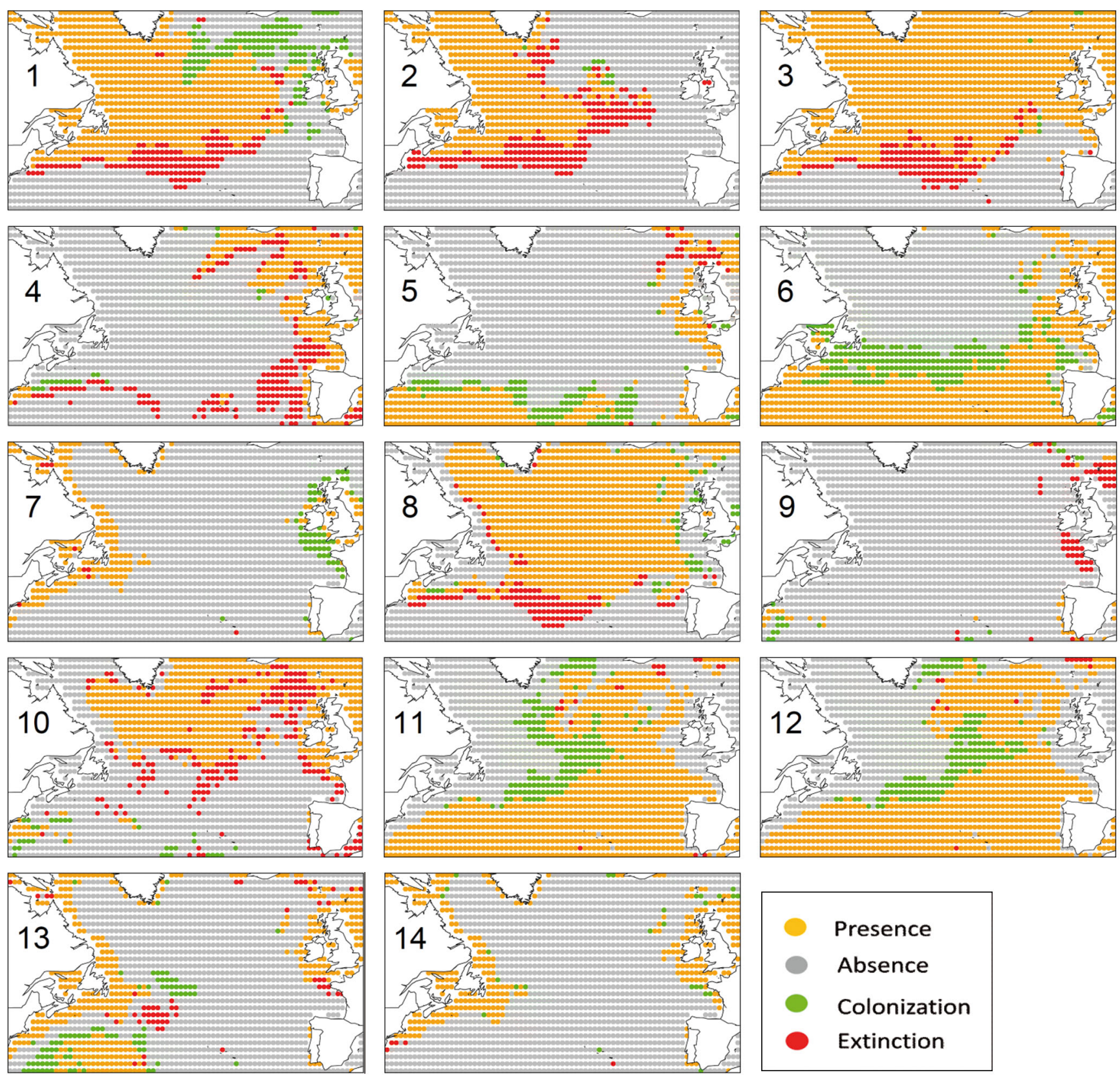

Fig. 7. Habitat suitability models for each of the species at present (2001-2020) and in future conditions (2080-2099). Green: colonization area, species was absent in present and present in future; red: extinction area, species was present at present and absent in future; orange: present in both periods; grey: absent in both periods; 1 : Calanus glacialis; 2: Calanus hyperboreus; 3 : Calanus finmarchicus; 4: Calanus helgolandicus; 5: Candacia armata; 6: Centropages typicus; 7: Centropages hamatus; 8: Paraeuchaeta norvegica; 9: Paraeuchaeta hebes; 10: Metridia lucens; 11: Pleuromamma borealis; 12: Pleuromamma robusta; 13: Pseudocalanus elongatus; 14: Temora longicornis

the Arctic C. glacialis and C. hyperboreus (Hirche 1991) at the northern edge of its distribution, i.e. north of Iceland, while in the northeastern North Atlantic, the North Sea and in the southern part of the Norwegian Sea, it co-occurs with C. helgolandicus (Conover 1988). Results also showed that the biogeographical range of C. glacialis and C. hyperboreus will be rather similar. The present biogeographic features of C. finmarchicus, C. hyperboreus and $C$. glacialis have been relatively well resolved by our habitat models. C. helgolandicus, instead, is more adapted to the temperate waters of the Atlantic Westerly Winds Biome (Longhurst 2007), although our projections have shown that it will mainly present 
Table 5. Latitudinal and longitudinal shift of the species in the North Atlantic by taking into account the gravity centre of each. The shift is calculated as the distance $(\mathrm{km})$ between the gravity centre of each species at present (2001-2020) and in the future (2080-2099)

\begin{tabular}{|c|c|c|}
\hline Species & $\begin{array}{l}\text { Latitudinal shift } \\
\text { (km per decade) }\end{array}$ & $\begin{array}{l}\text { Longitudinal shift } \\
\text { (km per decade) }\end{array}$ \\
\hline Calanus finmarchicus & 3.7 & 8.1 \\
\hline Calanus glacialis & 11.3 & 15.1 \\
\hline Calanus helgolandicus & 17.8 & 0.8 \\
\hline Calanus hyperboreus & 7.8 & -11.9 \\
\hline Candacia armata subpopulations $\mathrm{s}^{\mathrm{a}}$ & 1.9 & -10.8 \\
\hline Centropages hamatus subpopulations & -15.4 & -3.7 \\
\hline Centropages typicus & 2.2 & -0.8 \\
\hline Metridia lucens & 7.3 & -14.7 \\
\hline Paraeuchaeta hebes subpopulations ${ }^{\mathrm{a}}$ & 13.5 & -5.6 \\
\hline Paraeuchaeta norvegica & 12.8 & 9.6 \\
\hline Pleuromamma borealis & 7.2 & -4.7 \\
\hline Pleuromamma robusta & 11.2 & -3.4 \\
\hline Pseudocalanus elongatus & -11.0 & -20.6 \\
\hline Temora longicornis & 0.1 & 14.6 \\
\hline \multicolumn{3}{|c|}{$\begin{array}{l}{ }^{a} \text { The gravity centres of Candacia armata, Centropages hamatus and } \\
\text { Paraeuchaeta hebes are calculated by taking into account the individual } \\
\text { subpopulation patches of each species and averaging them }\end{array}$} \\
\hline
\end{tabular}

Centropages hamatus (15.4 km per decade) and Pseudocalanus elongatus (11 km per decade) will shift southward by the end of century. This could be because the southern colonized area of these 2 species is larger compared to the north area, yielding a net southward migration. SST is not the main driving effect in the distribution of these 2 continental shelf species assemblages $(6.6 \%$ out of the total $28.7 \%$ explained deviance in $C$. hamatus and $1.0 \%$ out of $17.6 \%$ in $P$. elongatus) and other environmental variables, such as $\mathrm{Pc}_{\mathrm{c}}$ appear to be more important. We think that although covering the whole biogeographic range of the species is preferable, the estimation of gravity centre considered here is relatively reliable to capture population shifts.

\section{Phenology changes}

Our models predicted an advance in the annual peaks of 12-13 d between present time and the end of the 21st century for C. finmarchicus and C. hyperboreus, which is in line with previous studies highlighting the advance in spring seasonal peaks for zooplankton time series; Edwards \& Richardson (2004) reported a $10 \mathrm{~d}$ advance in annual maxima in North Sea copepods from 1958 to 2002, while Greve et al. (2004) estimated an annual peak occurring 37 d earlier in Helgoland Road cladocerans from 1975 to 1999.

Zooplankton timing variability is often linked with temperature and/or phytoplankton during the preceding weeks or months (Ji et al. 2010). For taxa that have their maximum occurrences or abundances and activity in spring-summer like $C$. finmarchicus and C. hyperboreus, the usual pattern is 'earlier when warmer' (Edwards \& Richardson 2004, Mackas et al. 2007). Our projected seasonal peak of the 2 species is also occurring earlier, responding to a climate warming trend by the end of the century; these changes may propagate higher up in the food web.

Results of the phenology model showed that after the SST seasonal peak by mid-April, zooplankton maxima will occur: C. finmarchicus and C. hyperboreus showed a positive relationship with a 'sudden' increase in SST by the beginning of April. On the other hand, modelled phytoplankton blooms will only advance a week from the present to 2100 (data

Not all the species are projected to shift northward: 


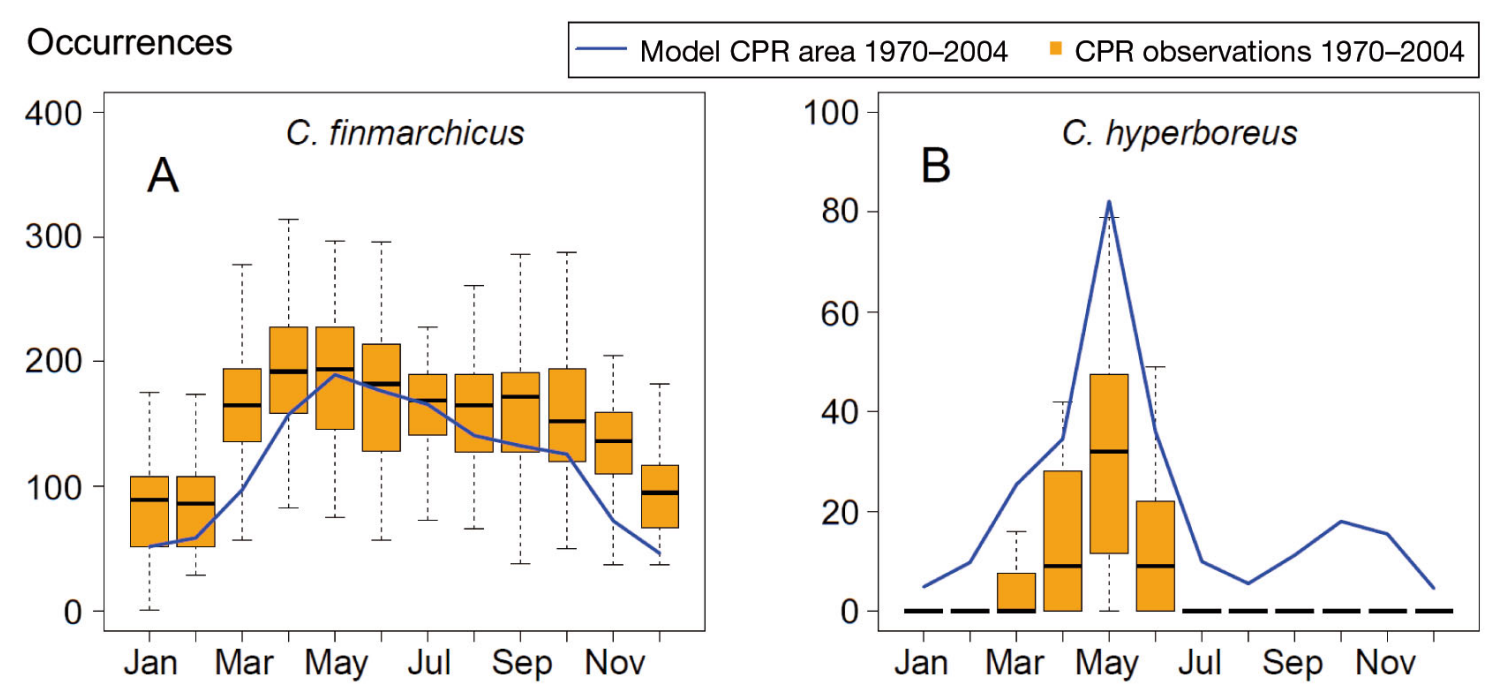

Predicted occurrences
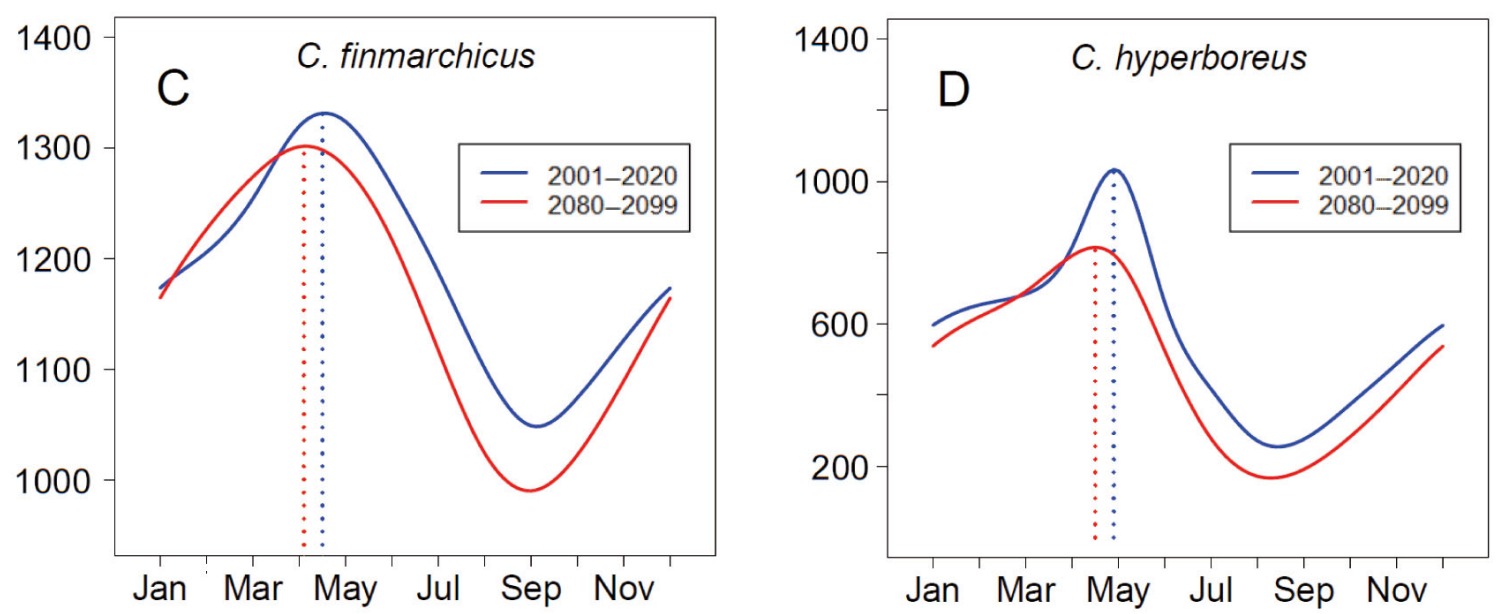

Fig. 8. (A) Calanus finmarchicus and (B) C. hyperboreus continuous plankton recorder (CPR) number of observations vs. the habitat model predictions for the CPR sampling area in 1970-2004. Predicted occurrence phenology of (C) C. finmarchicus and (D) C. hyperboreus at present (2001-2020) and future (2080-2099) in the whole study area. Vertical dotted lines represent the seasonal peak of each species at each period

not shown), which presumably shows a higher dependency on day length and light intensity rather than temperature (Eilertsen \& Wyatt 2000). Results also showed that phytoplankton blooms will occur 1 or 2 wk later than C. finmarchicus and C. hyperboreus annual peaks, underlining the higher dependence of these copepods on temperature rather than food availability. Melle et al. (2014) also reported positive relationships between maximum abundances of $C$. finmarchicus and maximum temperatures in the North Atlantic, with no clear relationship with Pc maximum.

The aforementioned phenology studies as well as our modelled phenology approach are spatially limited because they take into account only a subset of the entire geographic range of the species. If the overall distribution area had been analysed, we would not expect to obtain substantial shifts in phenology, since the species would shift poleward in the future to a similar thermal window where it could succeed. On the contrary, local studies of zooplankton phenology (e.g. Mackas et al. 1998) in a subarctic Pacific station (Bornhold et al. 1998, in the Strait of Georgia), reported higher shifts (30-60 d), since local environmental changes are subjected to more variability and the climatic response of the species will be more pronounced. Our spatial scale is in-between local and entire biogeographic range studies, which might explain the intermediate mean shifts values found. 

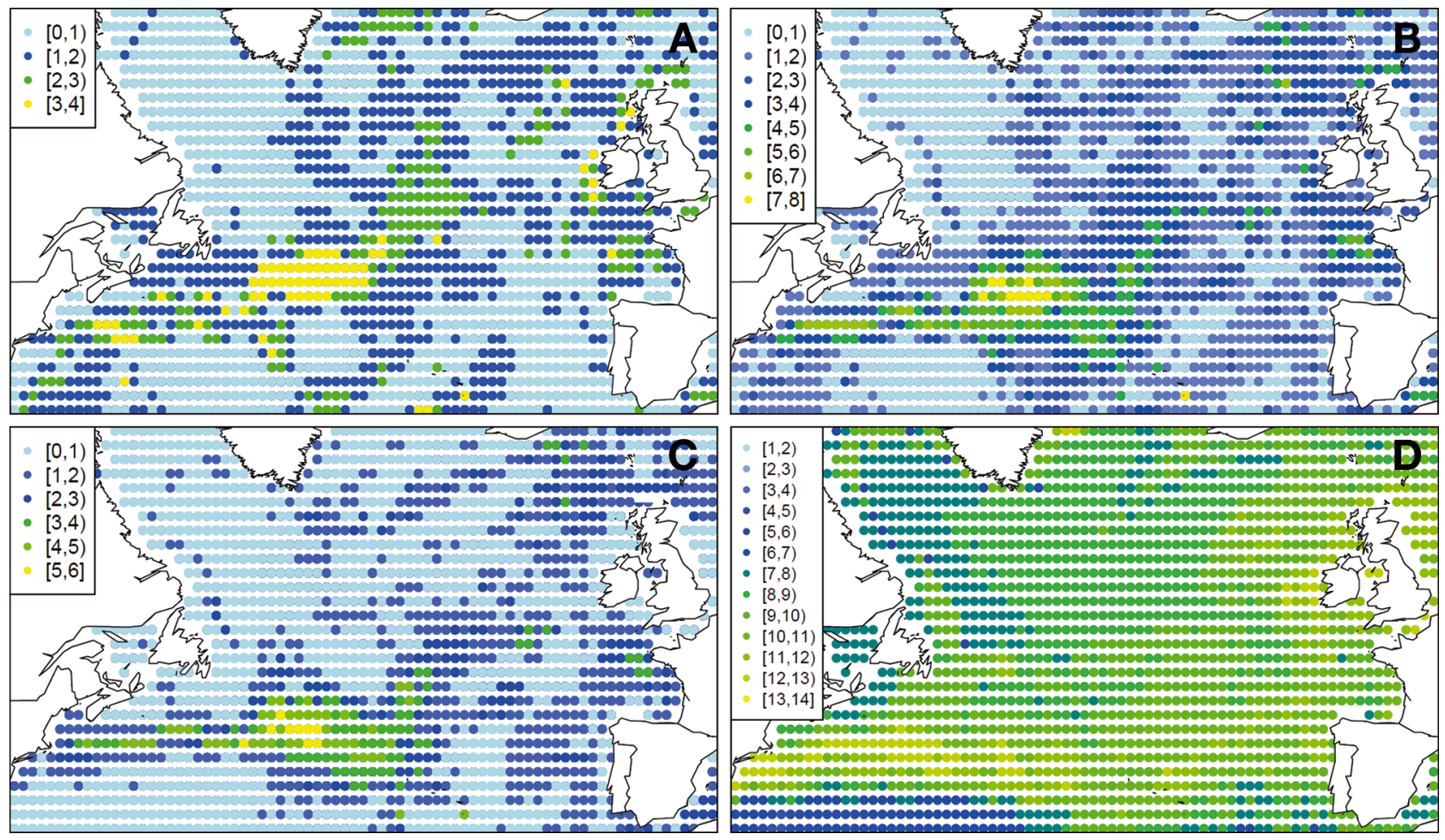

Fig. 9. (A) Turnover model: number of species that will either colonize or go extinct at each pixel by 2080-2099. (B) Extinction model: number of species that will disappear at each pixel by 2080-2099. (C) Colonization model: number of new species that will occur at each pixel by 2080-2099. (D) Species richness model at present (2001-2020)

\section{Species turnover}

Habitat models projected that the boundaries of species biogeographic domains are prone to suffer higher extinction or colonization rates. These areas with high turnover of species coincide with a large predicted SST increase by the end of century, where warm species assemblages could benefit to settle their populations there, while the southern limits of the cold subarctic and Arctic species assemblages will retract.

These projections, which follow basic constraints on the eco-physiology of animals (Tewksbury et al. 2008), support the theory that marine communities at the extreme ends of their ecological niche are especially sensitive to local extinction due to climate change. The retreat of the southern biogeographical limits of species leads to a general range constriction, and the poleward expansion of the species in the subpolar regions is limited by the availability of suitable habitats. The Oceanic Polar Front (Dietrich 1964) has acted as a sharp boundary for shelf edges and warm-temperate species associations limiting dispersal northward. These predicted species turnover patterns will trigger changes in the community structure of copepods, which are key species at the base of the marine food webs, and these changes may propagate through higher trophic levels (Kirby \& Beaugrand 2009, Chust et al. 2014b), having an ecosystem-wide effect on the North Atlantic marine provinces.

\section{Model uncertainties and implications}

Our study projects the spatial distribution of a representative subset of the North Atlantic copepod community. We have gained new insights on where the species are potentially able to expand or extinct locally. GAM-based distributions of Calanus spp. in the 1970-2004 period are in agreement with the observed spatial distribution from CPR surveys (Helaouët \& Beaugrand 2007), conventional sampling data sets (Heath et al. 2004, Reygondeau \& Beaugrand 2011), CPR data reconstruction studies (Chust et al. 2014a) and with other distribution studies inferred from models (Speirs et al. 2005, Durbin \& Kane 2007 , Kane \& Prezioso 2008, Hinder et al. 2014). Therefore, the general agreement of our models with occurrence records and other modelled distribution stud- 
ies supports the view that climatic (mainly SST), and also SSS, depth and biological (phytoplankton) factors are enough to provide a first approximation of niche shifts under climate warming (Pearson \& Dawson 2003, Araújo \& Guisan 2006).

In their simplest form, habitat suitability models are limited, since they ignore the adaptive potential of species. Indeed, there is some evidence that species may adapt to changing conditions with a rapid genetic response to natural selection instead of a direct reaction of the species following their ecological niche (Lavergne et al. 2010, Dam 2013). This has been documented for small and spatially isolated zooplankton such as Calanus helgolandicus (Yebra et al. 2011), or chaetognats (Peijnenburg et al. 2006) in the Northeast Atlantic, Mediterranean and Black Sea, but not in the North Atlantic for $C$. finmarchicus (Provan et al. 2009). On the other hand, niche conservatism has been observed on palaeoclimatic scales (Crisp et al. 2009). In this sense, we assumed that on the time scale of this study, zooplankton have a limited evolutionary response capability to climate change (Helaouët \& Beaugrand 2009, Reygondeau \& Beaugrand 2011 Stegert et al. 2010). Therefore, our projections assume no thermal adaptation of the species (sensu population fitness) to a changing environment. This assumption is supported by a recent study (Hinder et al. 2014) revealing that C. finmarchicus and $C$. helgolandicus show a lack of thermal adaptation to rising temperatures. Species that fail to acclimatize physiologically or evolve genetically to increasing temperature will either move northward following their habitats (Walther et al. 2002, Parmesan \& Yohe 2003, Hickling et al. 2006, Parmesan 2005, 2006, Thomas 2010) or become extinct (Thomas et al. 2004).

Successful shifting species may have characteristics similar to those postulated for successful introduced species, such as high dispersal rates, climatic tolerances and competitive abilities (Nyberg \&Wallentinus 2005). However, we have considered the Hutchinson fundamental niche concept with unlimited dispersal of species that does not consider species competition processes.

There are uncertainties related to our projections: first, to the climate model itself; second, to the habitat model; and third, to the coupling of both. Moreover, our models do not incorporate other ecological processes such as dispersal limitation (in a direct way) and population dynamics. Future research efforts should focus on including these 2 mechanisms in the habitat modelling frame, in the same way as has already been done for fishes and invertebrates (e.g.
Cheung et al. 2009). The application of the combined analytical methods beyond those traditionally used by ecologists will shed new light on the understanding of climate impacts on plankton communities.

We have addressed a community of copepods with different ecological requirements, though the use of statistical models (GAMs) is a more suitable approach than that of mechanistic models. GAMs offer the possibility to investigate the effect of climate change on multiple species without requiring sophisticated and time-consuming mechanistic models that depend on detailed knowledge of vital rates and life traits for each species (e.g. in C. finmarchicus or $C$. helgolandicus in Maps et al. 2011; see also Melle et al. 2014).

In summary, projections of 14 main copepod species in the North Atlantic by the end of the century under climate change scenarios indicate: (1) a prevailing poleward shift of most of the studied species, with poleward community shift of $8.7 \mathrm{~km}$ per decade on average, with an important species range variation from -15 to $18 \mathrm{~km}$ per decade; (2) an area characterized by high species turnover of local colonization and extinction located south of the Oceanic Polar Front where SST is projected to increase by the end of the century; and (3) an earlier seasonal peak of copepods in response to the ocean warming trend. All these changes may propagate higher up in the food web. The precision of projection changes is subjected to limitations of the data set, mainly for those species with low occurrences.

Acknowledgements. This research was funded by the European Commission (Contract No. 264933, EURO-BASIN: European Union Basin-Scale Analysis, Synthesis and Integration) and the Basque Government (Department Deputy of Agriculture, Fishing and Food Policy). We acknowledge CliSAP-Integrated Climate Data Center and NOAA for providing climate and bathymetry data, respectively. E.V. has benefited from a PhD Scholarship granted by the Iñaki Goenaga-Technology Centres Foundation. We are grateful to present and past staff of SAHFOS who have contributed to the maintenance of the CPR time series. The authors also acknowledge Markus Kreus, who has actively contributed providing data from HAMOCC and MPIOM models through DKRZ (www.dkrz.de/). This is contribution 710 from AZTITecnalia Marine Research Division.

\section{LITERATURE CITED}

Alheit J, Hagen E (1997) Long-term climate forcing of European herring and sardine populations. Fish Oceanogr 6: 130-139

Amante C, Eakins BW (2009) ETOPO1 1 arc-minute global relief model: procedures, data sources and analysis. NOAA Tech Memo NESDIS NGDC-24 
Araújo MB, Guisan A (2006) Five (or so) challenges for species distribution modelling. J Biogeogr 33:1677-1688

$>$ Beaugrand G (2003) Long-term changes in copepod abundance and diversity in the North-East Atlantic in relation to fluctuations in the hydroclimatic environment. Fish Oceanogr 12:270-283

Beaugrand G (2004) The North Sea regime shift: evidence, causes, mechanisms and consequences. Prog Oceanogr 60:245-262

> Beaugrand G (2009) Decadal changes in climate and ecosystems in the North Atlantic Ocean and adjacent seas. Deep-Sea Res Part II 56:656-673

> Beaugrand G (2012) Unanticipated biological changes and global warming. Mar Ecol Prog Ser 445:293-301

> Beaugrand G, Ibañez F (2002) Spatial dependence of calanoid copepod diversity in the North Atlantic Ocean. Mar Ecol Prog Ser 232:197-211

> Beaugrand G, Kirby RR (2010) Climate, plankton and cod. Glob Change Biol 16:1268-1280

$>$ Beaugrand G, Reid PC (2003) Long-term changes in phytoplankton, zooplankton and salmon related to climate. Global Change Biol 9:801-817

Beaugrand G, Reid PC, Ibañez F, Planque B (2000) Biodiversity of North Atlantic and North Sea calanoid copepods. Mar Ecol Prog Ser 204:299-303

> Beaugrand G, Reid PC, Ibañez F, Lindley JA, Edwards M (2002a) Reorganization of North Atlantic marine copepod biodiversity and climate. Science 296:1692-1694

Beaugrand G, Ibañez F, Lindley JA, Reid PC (2002b) Diversity of calanoid copepods in the North Atlantic and adjacent seas: species associations and biogeography. Mar Ecol Prog Ser 232:179-195

> Beaugrand G, Lindley JA, Helaouet P, Bonnet D (2007) Macroecological study of Centropages typicus in the North Atlantic Ocean. Prog Oceanogr 72:259-273

- Beaugrand G, Edwards M, Brander K, Luczak C, Ibañez F (2008) Causes and projections of abrupt climate-driven ecosystem shifts in the North Atlantic. Ecol Lett 11: 1157-1168

Beaugrand G, Christophe L, Martin E (2009) Rapid biogeographical plankton shifts in the North Atlantic Ocean. Glob Change Biol 15:1790-1803

> Beaugrand G, Lenoir S, Ibañez F, Manté C (2011) A new model to assess the probability of occurrence of a species, based on presence-only data. Mar Ecol Prog Ser 424:175-190

> Beaugrand G, Mackas D, Goberville E (2013) Applying the concept of the ecological niche and a macroecological approach to understand how climate influences zooplankton: advantages, assumptions, limitations and requirements. Prog Oceanogr 111:75-90

Bonnet D, Richardson A, Harris R, Hirst A and others (2005) An overview of Calanus helgolandicus ecology in European waters. Prog Oceanogr 65:1-53

Burnham KP, Anderson DR (2002) Model selection and multi-model inference: a practical information-theoretic approach, 2nd edn. Springer, New York, NY

> Calenge C, Darmon G, Basille M, Loison A, Jullien JM (2008) The factorial decomposition of the Mahalanobis distances in habitat selection studies. Ecology 89:555-566

> Cheung WWL, Lam VWY, Sarmiento JL, Kearney K, Watson R, Pauly D (2009) Projecting global marine biodiversity impacts under climate change scenarios. Fish Fish 10: 235-251

> Chust G, Irigoien X, Chave J, Harris RP (2013) Latitudinal phytoplankton distribution and the neutral theory of biodiversity. Global Ecol Biogeogr 22:531-543

Chust G, Castellani C, Licandro P, Ibaibarriaga L, Sagarminaga Y, Irigoien X (2014a) Are Calanus spp. shifting poleward in the North Atlantic? A habitat modelling approach. ICES J Mar Sci 71:241-253

Chust G, Allen JI, Bopp L, Schrum C and others (2014b) Biomass changes and trophic amplification of plankton in a warmer ocean. Glob Change Biol 20:2124-2139

Conover RJ (1988) Comparative life histories in the genera Calanus and Neocalanus in high latitudes of the northern hemisphere. Hydrobiologia 167-168:127-142

Crisp MD, Arroyo MTK, Cook LG, Gandolfo MA and others (2009) Phylogenetic biome conservatism on a global scale. Nature 458:754-756

Dam HG (2013) Evolutionary adaptation of marine zooplankton to global change. Annu Rev Mar Sci 5:349-370

de Boyer Montégut C, Madec G, Fischer AS, Lazar A, Iudicone D (2004) Mixed layer depth over the global ocean: an examination of profile data and a profile-based climatology. J Geophys Res C 109:C12003, doi:10.1029/2004 $\mathrm{JC} 002378$

deYoung B, Harris R, Alheit J, Beaugrand G, Mantua N, Shannon L (2004) Detecting regime shifts in the ocean: data considerations. Prog Oceanogr 60:143-164

Dietrich G (1964) Oceanic polar front survey. Rev Geophys 2:291-308

> Durbin E, Kane J (2007) Seasonal and spatial dynamics of Centropages typicus and C. hamatus in the western North Atlantic. Prog Oceanogr 72:249-258

Edwards M, Richardson, AJ (2004) Impact of climate change on marine pelagic phenology and trophic mismatch. Nature 430:881-884

Edwards M, Reid P, Planque B (2001) Long-term and regional variability of phytoplankton biomass in the Northeast Atlantic (1960-1995). ICES J Mar Sci 58:39-49

Eilertsen HC, Wyatt T (2000) Phytoplankton models and life history strategies. S Afr J Mar Sci 22:323-338

Elith J, Leathwick JR (2009) Species distribution models: ecological explanation and prediction across space and time. Annu Rev Ecol Evol Syst 40:677-697

- Elith J, Phillips SJ, Hastie T, Dudík M, Chee YE, Yates CJ (2011) A statistical explanation of maxent for ecologists. Divers Distrib 17:43-57

> Etherington TR, Ward AI, Smith GC, Pietravalle S, Wilson GJ (2009) Using the Mahalanobis distance statistic with unplanned presence-only survey data for biogeographical models of species distribution and abundance: a case study of badger setts. J Biogeogr 36:845-853

> Farber O, Kadmon R (2003) Assessment of alternative approaches for bioclimatic modeling with special emphasis on the Mahalanobis distance. Ecol Model 160:115-130

> Graham CH, Hijmans RJ (2006) A comparison of methods for mapping species ranges and species richness. Global Ecol Biogeogr 15:578-587

> Greve W, Reiners F, Nast J, Hoffmann S (2004) Helgoland Roads meso- and macrozooplankton time-series 1974 to 2004: lessons from 30 years of single spot, high frequency sampling at the only off-shore island of the North Sea. Helgol Mar Res 58:274-288

- Guisan A, Thuiller W (2005) Predicting species distribution: offering more than simple habitat models. Ecol Lett 8: 993-1009

Guisan A, Zimmermann NE (2000) Predictive habitat distribution models in ecology. Ecol Model 135:147-186 
Hanley JA, McNeil BJ (1982) The meaning and use of the area under a receiver operating characteristic (roc) curve. Radiology 143:29-36

Hastie TJ, Tibshirani RJ (1990) Generalized additive models, Chapman \& Hall, London

Head EJH, Harris LR, Yashayaev I (2003) Distributions of Calanus spp. and other mesozooplankton in the Labrador Sea in relation to hydrography in spring and summer (1995-2000). Prog Oceanogr 59:1-30

Heath MR, Boyle PR, Gislason A, Gurney WSC and others (2004) Comparative ecology of over-wintering Calanus finmarchicus in the northern North Atlantic, and implications for life-cycle patterns. ICES J Mar Sci 61:698-708

Helaouët P, Beaugrand G (2007) Macroecology of Calanus finmarchicus and C. helgolandicus in the North Atlantic Ocean and adjacent seas. Mar Ecol Prog Ser 345:147-165

Helaouët P, Beaugrand G (2009) Physiology, ecological niches and species distribution. Ecosystems 12:1235-1245

Helaouët P, Beaugrand G, Reid PC (2011) Macrophysiology of Calanus finmarchicus in the North Atlantic Ocean. Prog Oceanogr 91:217-228

> Hickling R, Roy DB, Hill JK, Fox R, Thomas CD (2006) The distributions of a wide range of taxonomic groups are expanding polewards. Glob Change Biol 12:450-455

Hijmans RJ (2012) Cross-validation of species distribution models: removing spatial sorting bias and calibration with a null model. Ecology 93:679-688

Hijmans RJ, Phillips S, Leathwick J, Elith J (2013) Dismo: species distribution modeling. R package version 0.8-17. http://CRAN.R-project.org/package=dismo (accessed 29 Aug 2013)

> Hinder SL, Gravenor MB, Edwards M, Ostle C and others (2014) Multi-decadal range changes vs. thermal adaptation for North East Atlantic oceanic copepods in the face of climate change. Glob Change Biol 20:140-146

> Hirche HJ (1991) Distribution of dominant calanoid copepod species in the Greenland Sea during late fall. Polar Biol 11:351-362

Hutchinson G (1957) Concluding remarks. Cold Spring Harbour Symp Quantitative Biology 22:415-427

> Ilyina T, Six KD, Segschneider J, Maier-Reimer E, Li H, Núñez-Riboni I (2013) Global ocean biogeochemistry model HAMOCC: model architecture and performance as component of the MPI-Earth system model in different CMIP5 experimental realizations. J Adv Model Earth Syst 5:287-315

IPCC (2007) Summary for policymakers. In: Solomon S, Qin D, Manning M, Chen Z and others (eds) Climate change 2007: the physical science basis. Contribution of working group I to the fourth assessment report of the Intergovernmental Panel on Climate Change. Cambridge University Press, Cambridge, p 1-18

> Irigoien X (2004) Some ideas about the role of lipids in the life cycle of Calanus finmarchicus. J Plankton Res 26: 259-263

> Irigoien X, Chust G, Fernandes JA, Albaina A, Zarauz L (2011) Factors determining the distribution and betadiversity of mesozooplankton species in shelf and coastal waters of the Bay of Biscay. J Plankton Res 33:1182-1192

> Ji R, Edwards M, Mackas DL, Runge JA, Thomas AC (2010) Marine plankton phenology and life history in a changing climate: current research and future directions. J Plankton Res 32:1355-1368

> Jiménez-Valverde A, Lobo JM (2007) Threshold criteria for conversion of probability of species presence to either-or presence-absence. Acta Oecol 31:361-369

Johns DG, Edwards M, Batten SD (2001) Arctic boreal plankton species in the Northwest Atlantic. Can J Fish Aquat Sci 58:2121-2124

> Jungclaus JH, Fischer N, Haak H, Lohmann K and others (2013) Characteristics of the ocean simulations in the Max Planck Institute Ocean Model (MPIOM) the ocean component of the MPI-Earth system model. J Adv Model Earth Syst 5:422-446

Kane J, Prezioso J (2008) Distribution and multi-annual abundance trends of the copepod Temora longicornis in the US northeast shelf ecosystem. J Plankton Res 30: $619-632$

Kirby RR, Beaugrand G (2009) Trophic amplification of climate warming. Proc R Soc Lond B 276:4095-4103

Kroeker KJ, Kordas RL, Crim RN, Singh GG (2010) Metaanalysis reveals negative yet variable effects of ocean acidification on marine organisms. Ecol Lett 13:1419-1434

Lavergne S, Mouquet N, Thuiller W, Ronce O (2010) Biodiversity and climate change: integrating evolutionary and ecological responses of species and communities. Annu Rev Ecol Evol Syst 41:321-350

> Lee S-K, Park W, van Sebille E, Baringer MO and others (2011) What caused the significant increase in Atlantic Ocean heat content since the mid-20th century? Geophys Res Lett 38:L17607, doi:10.1029/2011GL048856

> Levitus S (1983) Climatological atlas of the world ocean. Eos Trans Am Geophys Union 64:962-963

Longhurst AR (2007) Ecological geography of the sea, 2nd edn. Academic Press, Burlington, MA, p 51-70

> Mackas DL, Goldblatt R, Lewis AG (1998) Interdecadal variation in developmental timing of Neocalanus plumchrus populations at ocean station $\mathrm{P}$ in the subarctic North Pacific. Can J Fish Aquat Sci 55:1878-1893

> Mackas DL, Batten S, Trudel M (2007) Effects on zooplankton of a warmer ocean: recent evidence from the Northeast Pacific. Prog Oceanogr 75:223-252

Mahalanobis PC (1936) On the generalized distance in statistics. Proc Natl Inst Sci India 2:49-55

> Maps F, Pershing AJ, Record NR (2011) A generalized approach for simulating growth and development in diverse marine copepod species. ICES J Mar Sci 69: 370-379

Marsland SJ, Haak H, Jungclaus JH, Latif M, Röske F (2003) The Max-Planck-Institute global ocean/sea ice model with orthogonal curvilinear coordinates. Ocean Model 5: 91-127

Mauchline J (1998) Preface. In: Mauchline J (ed) The biology of calanoid copepods. Advances in marine biology, Vol. 33. Academic Press, San Diego, CA

> Melle W, Runge JA, Head E, Plourde S and others (2014) The North Atlantic Ocean as habitat for Calanus finmarchicus: environmental factors and life history traits. Prog Oceanogr 129:244-284

> Molinero JC, Ibanez F, Souissi S, Buecher E, Dallot S, Nival $P$ (2008) Climate control on the long-term anomalous changes of zooplankton communities in the northwestern Mediterranean. Glob Change Biol 14:11-26

Møller EF, Maar M, Jónasdóttir SH, Nielsen TG, Tönnesson $\mathrm{K}$ (2012) The effect of changes in temperature and food on the development of Calanus finmarchicus and Calanus helgolandicus populations. Limnol Oceanogr 57: 211-220

Monterroso P, Brito JC, Ferreras P, Alves PC (2009) Spatial ecology of the European wildcat in a Mediterranean eco- 
system: dealing with small radio-tracking datasets in species conservation. J Zool 279:27-35

- Moore PJ, Thompson RC, Hawkins SJ (2011) Phenological changes in intertidal con-specific gastropods in response to climate warming. Glob Change Biol 17:709-719

Nogués-Bravo D, Rodríguez J, Hortal J, Batra P, Araújo MB (2008) Climate change, humans, and the extinction of the woolly mammoth. PLoS Biol 6:e79

Nyberg C, Wallentinus I (2005) Can species traits be used to predict marine macroalgal introductions? Biol Invasions 7:265-279

Oksanen J, Minchin PR (2002) Continuum theory revisited: what shape are species responses along ecological gradients? Ecol Model 157:119-129

> Orr JC, Fabry VJ, Aumont O, Bopp L and others (2005) Anthropogenic ocean acidification over the twenty-first century and its impact on calcifying organisms. Nature 437:681-686

Parmesan C (2005) Biotic response: range and abundance changes. In: Lovejoy TE, Hannah, L (eds) Climate change and biodiversity. Yale University Press, New Haven, CT, p 41-55

> Parmesan C (2006) Ecological and evolutionary responses to recent climate change. Annu Rev Ecol Evol Syst 37: 637-669

Parmesan C, Yohe G (2003) A globally coherent fingerprint of climate change impacts across natural systems. Nature 421:37-42

Pearson RG, Dawson TP (2003) Predicting the impacts of climate change on the distribution of species: Are bioclimate envelope models useful? Global Ecol Biogeogr 12:361-371

> Peijnenburg KT, Fauvelot C, Breeuwer JA, Menken SB (2006) Spatial and temporal genetic structure of the planktonic Sagitta setosa (chaetognatha) in European seas as revealed by mitochondrial and nuclear DNA markers. Mol Ecol 15:3319-3338

> Perry AL, Low PJ, Ellis JR, Reynolds JD (2005) Climate change and distribution shifts in marine fishes. Science 308:1912-1915

> Phillips SJ, Anderson RP, Schapire RE (2006) Maximum entropy modeling of species geographic distributions. Ecol Model 190:231-259

Pomerleau C, Nelson RJ, Hunt BPV, Sastri AR, Williams WJ (2014) Spatial patterns in zooplankton communities and stable isotope ratios $\left(\delta^{13} \mathrm{C}\right.$ and $\left.\delta^{15} \mathrm{~N}\right)$ in relation to oceanographic conditions in the sub-Arctic Pacific and western Arctic regions during the summer of 2008. J Plankton Res 36:757-775

> Provan JIM, Beatty GE, Maggs CA, Savidge G (2007) Expressed sequence tag-derived microsatellites for the cool-water marine copepod Calanus finmarchicus. Mol Ecol Notes 7:1369-1371

Provan J, Beatty GE, Keating SL, Maggs CA, Savidge G (2009) High dispersal potential has maintained longterm population stability in the North Atlantic copepod Calanus finmarchicus. Proc R Soc B 276:301-307

> Raes N, ter Steege H (2007) A null-model for significance testing of presence-only species distribution models. Ecography 30:727-736

Reid PC, Borges Md F, Svendsen E (2001) A regime shift in the North Sea circa 1988 linked to changes in the North
Sea horse mackerel fishery. Fish Res 50:163-171

> Reygondeau G, Beaugrand G (2011) Future climate-driven shifts in distribution of Calanus finmarchicus. Glob Change Biol 17:756-766

- Richardson AJ (2008) In hot water: zooplankton and climate change. ICES J Mar Sci 65:279-295

> Richardson AJ, Schoeman DS (2004) Climate impact on plankton ecosystems in the Northeast Atlantic. Science 305:1609-1612

> Sorte CJB, Williams SL, Carlton JT (2010) Marine range shifts and species introductions: comparative spread rates and community impacts. Global Ecol Biogeogr 19: 303-316

Speirs DC, Gurney WSC, Heath MR, Wood SN (2005) Modelling the basin-scale demography of Calanus finmarchicus in the North-east Atlantic. Fish Oceanogr 14:333-358

> Stegert C, Ji R, Davis CS (2010) Influence of projected ocean warming on population growth potential in two North Atlantic copepod species. Prog Oceanogr 87:264-276

> Tewksbury JJ, Huey RB, Deutsch CA (2008) Putting the heat on tropical animals. Science 320:1296-1297

- Thomas CD (2010) Climate, climate change and range boundaries. Divers Distrib 16:488-495

Thomas CD, Cameron A, Green RE, Bakkenes M and others (2004) Extinction risk from climate change. Nature 427: $145-148$

VanDerWal J, Falconi L, Januchowski S, Shoo L, Storlie C. (2012) Species distribution modelling tools: tools for processing data associated with species distribution modelling exercises. R Package 'SDMTools'. http://cran. r-project.org/web/packages/SDMTools/SDMTools.pdf

- Walther G-R, Post E, Convey P, Menzel A and others (2002) Ecological responses to recent climate change. Nature 416:389-395

> Warner AJ, Hays GC (1994) Sampling by the continuous plankton recorder survey. Prog Oceanogr 34:237-256

> Wilcoxon F (1945) Individual comparisons by ranking methods. Biom Bull 1:80-83

Woillez M, Rivoirard J, Petitgas P (2009) Notes on surveybased spatial indicators for monitoring fish populations. Aquat Living Resour 22:155-164

Wood S (2006) Generalized additive models: an introduction with R. CRC Academic Press, Boca Raton, FL

Woodd-Walker RS, Ward P, Clarke A (2002) Large-scale patterns in diversity and community structure of surface water copepods from the Atlantic Ocean. Mar Ecol Prog Ser 236:189-203

> Yates CJ, McNeill A, Elith J, Midgley GF (2010) Assessing the impacts of climate change and land transformation on banksia in the south west Australian floristic region. Divers Distrib 16:187-201

Yebra L, Bonnet D, Harris RP, Lindeque PK, Peijnenburg KTCA (2011) Barriers in the pelagic: population structuring of Calanus helgolandicus and C. euxinus in European waters. Mar Ecol Prog Ser 428:135-149

> Young BE, Franke I, Hernandez PA, Herzog SK, Paniagua L, Tovar C, Valqui T (2009) Using spatial models to predict areas of endemism and gaps in the protection of Andean slope birds. Auk 126:554-565

Zuur AF, Ieno EN, Walker N (2009) Mixed effects models and extensions in ecology with $\mathrm{R}, 1$ st edn. Springer-Verlag, New York, NY 


\section{Appendix}
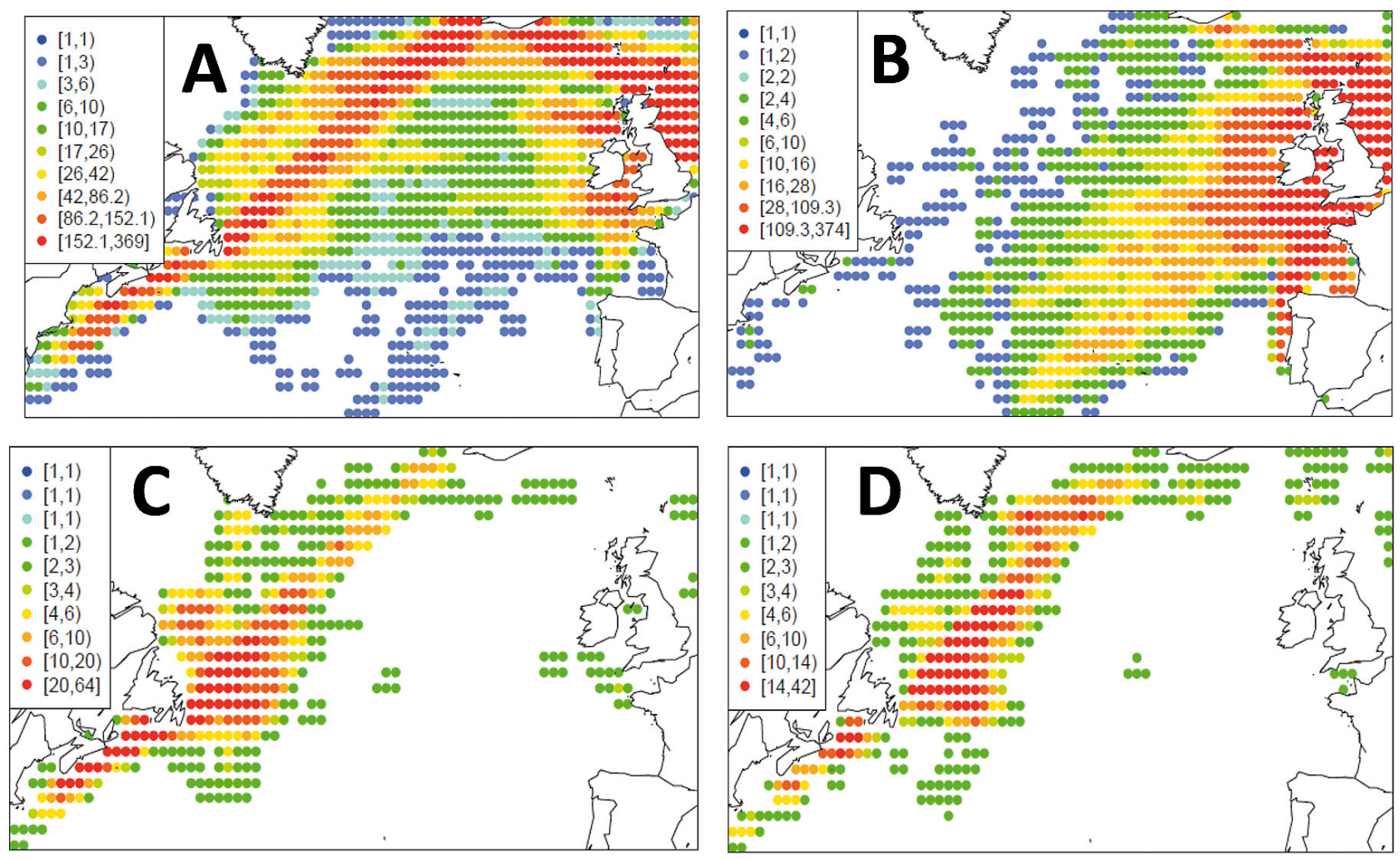

Fig. A1. Number of Calanus spp. occurrences (ind. $\mathrm{m}^{-3}$ ) from continuous plankton recorder survey for the 1970-2004 period. (A) C. finmarchicus, (B) C. helgolandicus, (C) C. glacialis and (D) C. hyperboreus 
I

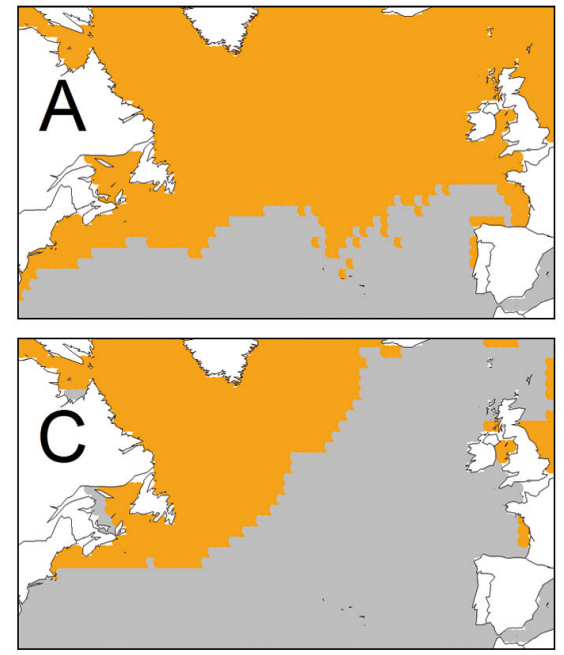

II
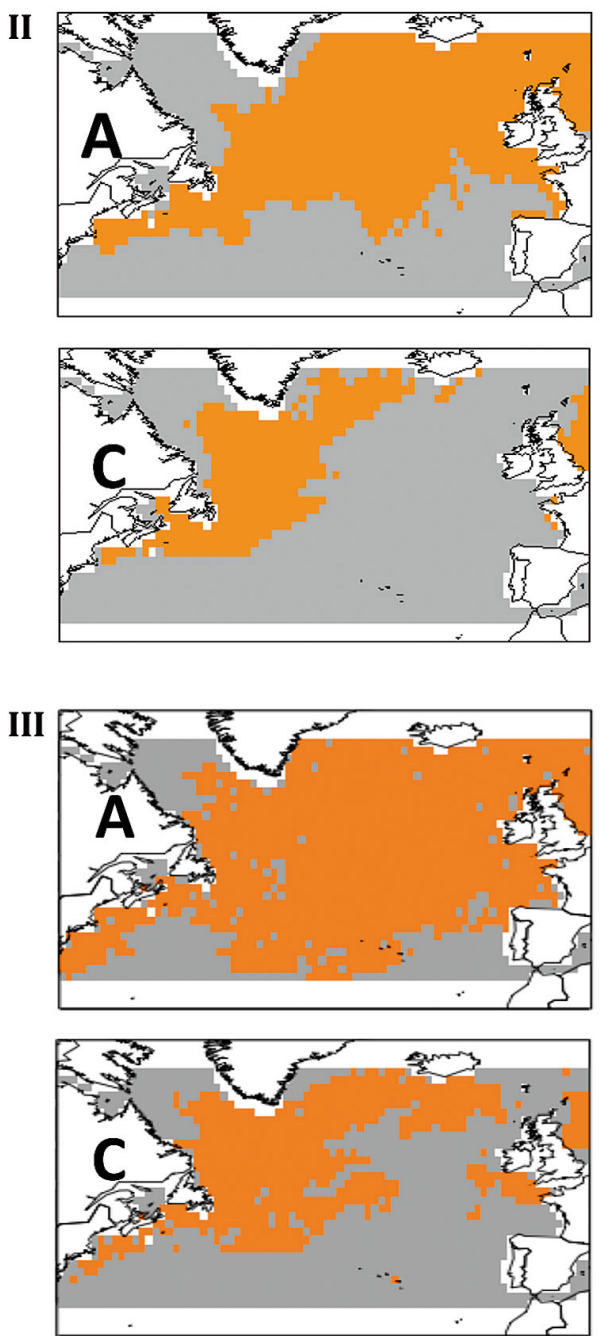
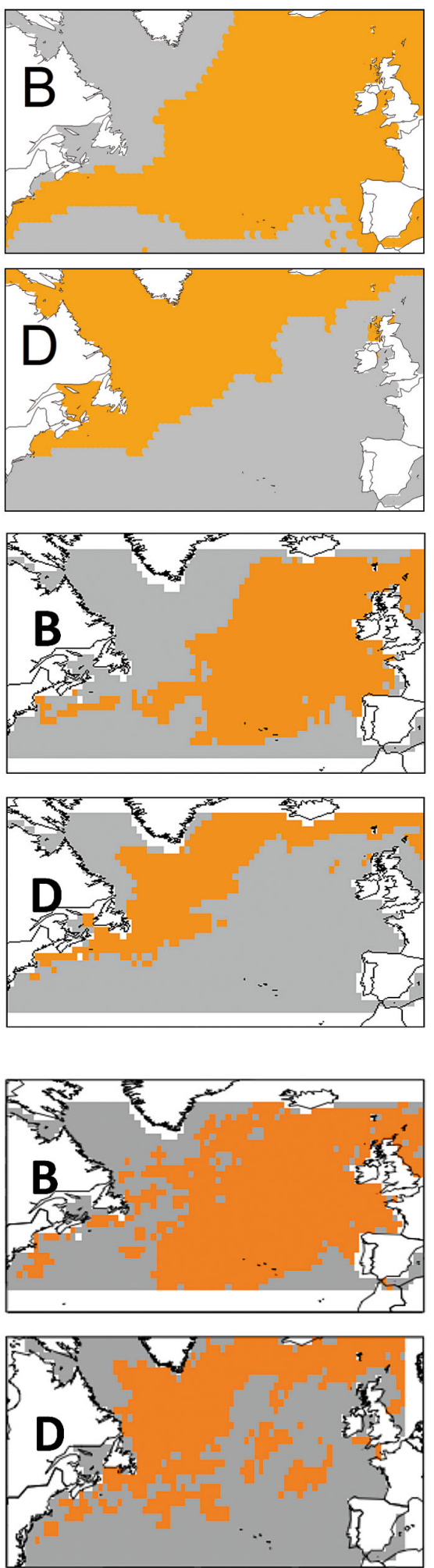

Fig. A2. Presence-absence model of Calanus spp. in the 1970-2004 period (all months and years aggregated). Orange: presence; grey: absence. (A) C. finmarchicus, (B) C. helgolandicus, (C) C. glacialis and (D) C. hyperboreus. Models: (I) Generalized Additive Model, (II) MaxEnt and (III) Mahalanobis

Editorial responsibility: Antonio Bode, A Coruña, Spain
Submitted: September 4, 2014; Accepted: March 25, 2015

Proofs received from author(s): June 17, 2015 